\title{
The atmospheric entry of fine-grained micrometeorites: The role of volatile gases in heating and fragmentation
}

\author{
M. D. SUTTLE (iD ${ }^{1,2,3^{*}}$, M. J. GENGE (iD ${ }^{1,2}$, L. FOLCO $^{3}$, M. VAN GINNEKEN ${ }^{4,5}$, Q. LIN ${ }^{1}$, \\ S. S. RUSSELL ${ }^{2}$, and J. NAJORKA ${ }^{2}$ \\ ${ }^{1}$ Department of Earth Science and Engineering, Imperial College London, South Kensington, London SW7 2AZ, UK \\ ${ }^{2}$ Department of Earth Science, The Natural History Museum, Cromwell Rd, London SW7 5BD, UK \\ ${ }^{3}$ Dipartimento di Scienze della Terra, Università di Pisa, 56126 Pisa, Italy \\ ${ }^{4}$ Analytical, Environmental and Geo-Chemistry (AMGC), Vrije Universiteit Brussel, Av. F.D. Roosevelt 50, \\ 1050 Brussels, Belgium \\ ${ }^{5}$ Laboratoire G-Time, Université Libre de Bruxelles, Franklin Rooseveltlaan 50, 1050 Brussels, Belgium \\ *Corresponding author. E-mail: mds10@ic.ac.uk
}

(Received 04 December 2017; revision accepted 27 October 2018)

\begin{abstract}
The early stages of atmospheric entry are investigated in four large $(250-950 \mu \mathrm{m})$ unmelted micrometeorites (three fine-grained and one composite), derived from the Transantarctic Mountain micrometeorite collection. These particles have abundant, interconnected, secondary pore spaces which form branching channels and show evidence of enhanced heating along their channel walls. Additionally, a micrometeorite with a doublewalled igneous rim is described, suggesting that some particles undergo volume expansion during entry. This study provides new textural data which links together entry heating processes known to operate inside micrometeoroids, thereby generating a more comprehensive model of their petrographic evolution. Initially, flash heated micrometeorites develop a melt layer on their exterior; this igneous rim migrates inwards. Meanwhile, the particle core is heated by the decomposition of low-temperature phases and by volatile gas release. Where the igneous rim acts as a seal, gas pressures rise, resulting in the formation of interconnected voids and higher particle porosities. Eventually, the igneous rim is breached and gas exchange with the atmosphere occurs. This mechanism replaces inefficient conductive rim-to-core thermal gradients with more efficient particle-wide heating, driven by convective gas flow. Interconnected voids also increase the likelihood of particle fragmentation during entry and, may therefore explain the rarity of large fine-grained micrometeorites among collections.
\end{abstract}

\section{INTRODUCTION}

Micrometeorites are millimeter-sized (10-2000 $\mu \mathrm{m})$ extraterrestrial dust grains (Rubin and Grossman 2010) derived from recently disrupted asteroids (Nesvorný et al. 2003, 2006) and sublimating short-period comets (Schulz et al. 2004; Nesvorný et al. 2010). The current flux of micrometeorites exceeds 20,000 tons per year (Love and Brownlee 1993; Peucker-Ehrenbrink 1996; Zolensky et al. 2006) and is dominated by fine-grained, hydrated, chondritic matrix with genetic affinities to CM, CR, and CI chondrites (Kurat et al. 1994; Genge et al. 1997; Taylor et al. 2012). However, because entry speeds are high $\left(>11 \mathrm{~km} \mathrm{~s}^{-1}\right)$ and particles are small
$(<2000 \mu \mathrm{m}), \quad>90 \%$ of the impinging dust flux is completely vaporized during atmospheric entry (Love and Brownlee 1991; Taylor et al. 1998).

The remaining material that survives atmospheric entry is subclassified based on the degree of thermal reprocessing experienced (Genge et al. 2008). Particles are designated as either unmelted, partially melted $(>50 \%$ melt fraction and termed scoriaceous), or completely melted $(>80 \%$ melt fraction and termed cosmic spherules) (Genge et al. 2008). The ratio of unmelted-tomelted micrometeorites, estimated by empirical observation from micrometeorite collections, varies widely. Approximately $70 \%$ of particles collected from Antarctic snow (Dobrică et al. 2009) are unmelted; 
however, this drops to $30 \%$ among Greenland ice collections (Maurette et al. 1987), while unmelted particles are exceedingly rare in glacial moraine collections ( $\ll 1 \%$, Suttle et al. 2015; Genge et al. 2018) and entirely absent from urban micrometeorite collections (Genge et al. 2017). This reflects the combined effects of atmospheric entry and terrestrial weathering, as well as human sampling and recovery biases. Despite these factors, unmelted micrometeorites appear considerably less common than their unmelted counterparts (Suavet et al. 2009). Furthermore, the abundance of unmelted particles also decreases as particle size increases. For example, among the South Pole Water Well (SPWW) collection, Taylor et al. (2007) demonstrated that unmelted micrometeorites $>150 \mu \mathrm{m}$ in size compose $<10 \%$ of micrometeorite collections, while unmelted micrometeorites $>250 \mu \mathrm{m}$ in size total $<1 \%$ of micrometeorite collections.

Large, unmelted micrometeorites are, therefore, rare and significantly understudied. At present, the only publication which investigates the petrography of unmelted micrometeorites with sizes $>250 \mu \mathrm{m}$ is Van Ginneken et al. (2012), in which eight micrometeorites are analyzed and their affinities to carbonaceous and ordinary chondrites demonstrated. However, even in these unmelted micrometeorites, passage through the atmosphere has resulted in a significant overprint of parent body petrography (Genge et al. 1997; Genge 2006; Taylor et al. 2011, 2012). It is, therefore, essential that the mechanisms of thermal processing which operate in micrometeorites are well constrained and can be confidently distinguished from pre-atmospheric parent body processes.

Prior to partial melting and the formation of scoriaceous micrometeorites, the early stages of entry heating are characterized by the decomposition of lowtemperature phases $\left(<1000{ }^{\circ} \mathrm{C}\right)$ held within the micrometeorite core (Toppani et al. 2001; Nozaki et al. 2006; Taylor et al. 2011) and the formation of a thin melt rim on the particle exterior (Toppani and Libourel 2003; Genge 2006). Genge et al. (2017) demonstrated how hydrated fine-grained micrometeorites can support extremely high thermal gradients during entry, through the progressive thermal decomposition and melting of water-bearing phyllosilicates at the particle margin. Thus, it would appear that most small fine-grained micrometeorites maintain core-to-rim thermal gradients by conductive heating during atmospheric deceleration. However, experimental studies have also provided new insights with contrasting conclusions. By flash heating micrometeorite analogs, Court and Tan (2016) revealed how the generation of volatile gases, formed by decomposing sulfides and their subsequent interaction with organics in secondary carbothermic reactions potentially plays a role in micrometeoroid evolution through degassing.

In this study, we investigate four large $(>250 \mu \mathrm{m})$ micrometeorites, from the Transantarctic Mountain (TAM) micrometeorite collection (Rochette et al. 2008); they are primarily composed of fine-grained matrix and share similar geochemical and textural features. This includes three fine-grained micrometeorites and one composite micrometeorite - containing a mantle of finegrained matrix surrounding a coarse-grained, compact igneous core. This is equivalent to the composite micrometeorites described by Genge et al. (2005) from the Cap Prud'homme collection. Most notably, each of the micrometeorites studied here contains an abundance of interconnected voids and cracks, resulting in high particle porosities, lower densities, and lower mechanical strengths. These void networks are of interest because they may be related to volatile gas release and, therefore, formed during atmospheric entry heating. We explore this hypothesis using a combination of microanalysis techniques to investigate each particle's micro-textures, geochemistry, and mineralogy.

\section{METHODS}

Four large unmelted micrometeorites were selected from the TAM micrometeorite collection and analyzed at the Natural History Museum (NHM), London. Data were collected in the museum's core research laboratories: Imaging and Analysis Centre. Particles were investigated under scanning electron microscope (SEM), using backscattered electron imaging (BEI), electron microprobe analysis (EMPA) (either standard-based energy dispersive spectroscopy [EDS] or wave dispersive spectroscopy [WDS]), elemental X-ray mapping, and micro-X-ray diffraction ( $\mu \mathrm{XRD})$. Mid-IR spectroscopic data were also collected at Diamond Lightsource. In addition, a single particle, TAM37P-03, was analyzed using $\mu \mathrm{CT}$ at Imperial College London's Petroleum engineering rock mechanics facility. This particle was then crushed, and some fragments embedded in resin for EDS analysis and backscattered electron (BSE) imaging of the internal textures. The data types collected for each micrometeorite are shown in Table 1.

\section{Geochemical Analysis}

Geochemical data were acquired from the polished and carbon-coated micrometeorite cross sections using either a Cameca SX100 SEM equipped with five wave dispersive spectrometers (WDS) or a Zeiss SEM-EVO 15LS fitted with an Oxford Instruments' $80 \mathrm{~mm}^{2} \mathrm{X}$ Max silicon drift detector (SSD) energy dispersive spectrometer (EDS). All analyses were performed under 
Table 1. Analysis types performed on each micrometeorite.

\begin{tabular}{|c|c|c|c|c|c|c|c|}
\hline Sample & BEI (external) & BEI (internal) & EMPA & Mid-IR & X-ray element map & $\mu \mathrm{XRD}$ & $\mu \mathrm{CT}$ \\
\hline TAM19-7 & & - & - & - & - & - & \\
\hline TAM19B-7 & & - & - & - & - & - & \\
\hline TAM2.1Q & & - & - & - & - & & \\
\hline TAM37P-03 & - & - & - & - & & - & - \\
\hline
\end{tabular}

acceleration voltages of $20 \mathrm{kV}$, beam currents of $10 \mathrm{nA}$ or $3 \mathrm{nA}$ respectively, and a focused beam spot $(<1 \mu \mathrm{m}$ diameter).

The Cameca SX100 was calibrated prior to operation using a suite of mineral standards, specific to each element under detection. Standards include but were not limited to: forsterite $\left(\mathrm{Mg}_{2} \mathrm{SiO}_{4}\right)$ (San Carlos olivine) for calibration of $\mathrm{Mg}$, hematite $\left(\mathrm{Fe}_{2} \mathrm{O}_{3}\right)$ for $\mathrm{Fe}$ calibration, wollastonite $\left(\mathrm{CaSiO}_{3}\right)$ for $\mathrm{Si}$ and $\mathrm{Ca}$ calibration, and corundum $\left(\mathrm{Al}_{2} \mathrm{O}_{3}\right)$ for $\mathrm{Al}$ calibration. After analysis, the in-house Cameca PAP matrix correction software was used to remove artefacts arising from atomic number, absorption, and secondary fluorescence effects. Elemental detection limits for this instrument are on the order of $0.02-0.05 \mathrm{wt} \%$ and elemental uncertainties vary between 0.01 and $0.03 \mathrm{wt} \%$.

Geochemical data obtained using the Zeiss SEMEVO followed the best practice requirements for standard-based EDS analysis, as outlined by Newbury and Ritchie (2012). Pre-analysis gain calibrations using an elemental cobalt standard provided widely separated energy peaks for accurate peak position and intensity validation. In addition, throughout data collection, routine monitoring of beam current $(3 \mathrm{nA})$, count dead times $(\sim 30 \%)$, acceleration voltages $(20 \mathrm{kV})$, and sampledetector distance $(8.5 \mathrm{~mm})$ ensured ideal conditions were maintained. Post-acquisition data processing was performed by the Oxford Instruments INCA software, which applies standard ZAF matrix corrections. Weight totals were determined through calculation of oxygen content by stoichiometry and assuming all cations occupied their lowest oxidation states (e.g., all Fe was assumed to be $\mathrm{Fe}^{2+}$ ). Under these analytical parameters, quantitative SEM-EDS analyses of silicate and oxide phases produce reliable, high-accuracy results with detection limits on the order of $0.2 \mathrm{wt} \%$ and analytical uncertainties between 0.1 and $0.5 \mathrm{wt} \%$.

Most geochemical analyses were obtained on the higher precision Cameca SX100 by EMPA-WDS; however, some phase identifications and the matrix analyses on TAM37P-03 were collected using the standard-based EDS system. We rejected analyses whose weight totals were $<80 \mathrm{wt} \%$.

Bulk chemical compositions for each micrometeorite were determined by collecting and averaging $>15$ randomly selected spot analyses from the particle's finegrained matrix. A sample of CI Ivuna obtained, by research loan, from the NHM (sample no. P16384) provided a reference standard for chondritic CI values (see the spider diagram shown in Fig. 1).

\section{Elemental X-Ray Mapping}

A FEI Quanta 650 field emission gun SEM equipped with a Bruker Flat Quad 5060F EDS detector plate was employed to collect high-resolution semiquantitative Xray element maps for three of the micrometeorites (TAM19-7, TAM19B-7, and TAM2.1Q). These maps reveal element distribution and partitioning at ultrahigh spatial resolution $\left(\sim 1.5 \mu \mathrm{m}^{2}\right.$ per pixel) and, therefore, aid in the identification of micron-scale phases and in the investigation of atmospheric entry processes (Salge et al. 2017). These X-ray maps were acquired using a $12 \mathrm{kV}$ electron beam. This is the minimum voltage necessary to fully excite the Fe-K $\alpha$ line $(\sim 6.4 \mathrm{keV}$; Merlet and Llovet 2012), and, therefore, achieves accurate quantification of elemental abundance, while also minimizing the interaction volume and, therefore, increasing the spatial resolution of the data collected. The electron beam rastered over the particle's cross section surface for 2$24 \mathrm{~h}$, generating a hyperspectral map from which spectra could be extracted. Count rate outputs of $27.7 \mathrm{kcps}$ and dead times between 5 and $10 \%$ were maintained throughout acquisition.

\section{Micro-X-Ray Diffraction}

A Rigaku Rapid II micro-diffraction system, equipped with a 2-D curved imaging plate detector was employed to collect diffraction pattern data from three of the four micrometeorites (TAM19-7, TAM19B-7, and TAM37P-03). A Cu X-ray source with an incident beam monochromator provided a clean, continuous $\mathrm{Cu}-\mathrm{K} \alpha$ radiation source $(1.5418 \AA)$. This was collimated by a pinhole system to a beam spot of $100 \mu \mathrm{m}$ (TAM19-7 and TAM1917B) or $300 \mu \mathrm{m}$ (TAM37P-03). Each sample analysis ran for approximately $20 \mathrm{~h}$. The 2-D diffraction image was converted to a 1-D XRD pattern following automated removal of the background signal and integration of the Debye rings. Data from TAM19- 


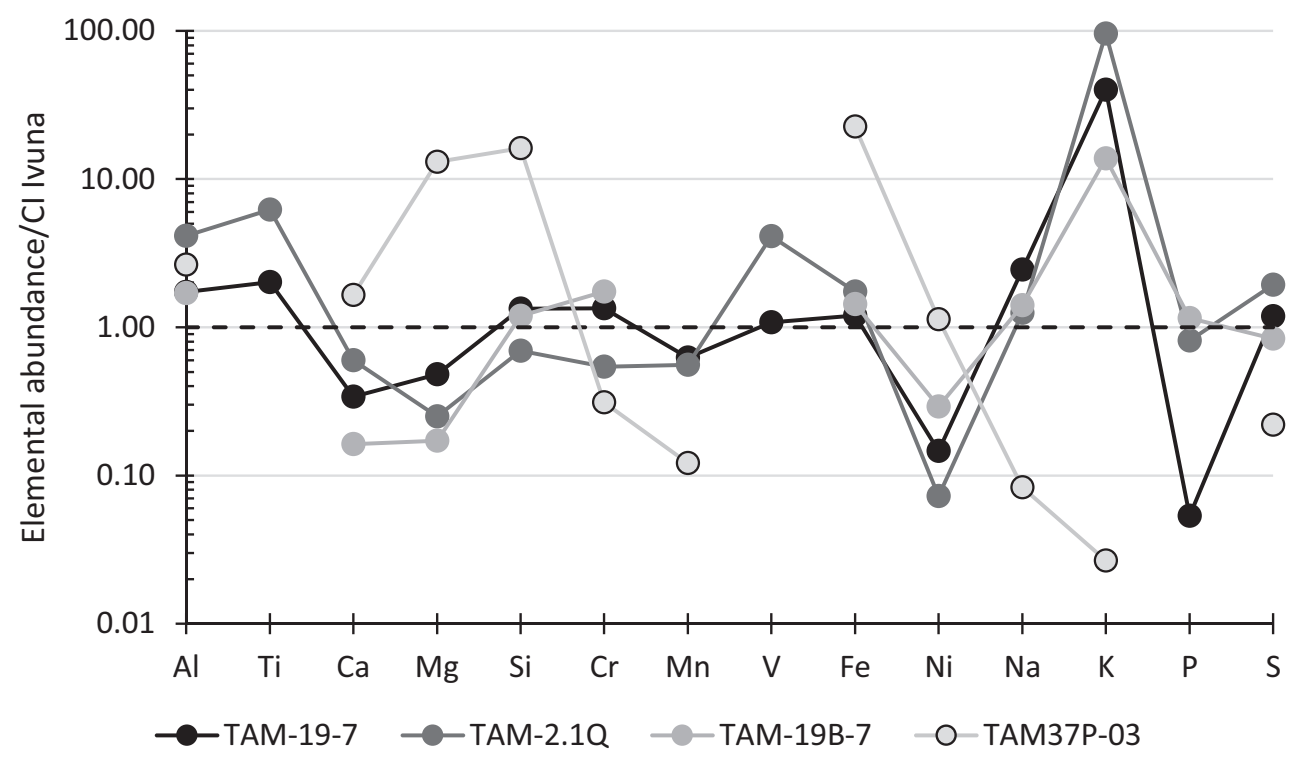

Fig. 1. Elemental abundance patterns for all four TAM micrometeorites. Values are normalized against CI chondrite composition, using a chip of Ivuna as a reference standard (and whose composition is shown in Table 1). Elements ordered in increasing volatility. All micrometeorites show similar geochemical profiles, characterized by broadly chondritic compositions. Depletions in $\mathrm{Ni}$ and $\mathrm{P}$ and enrichments in $\mathrm{K}$ and $\mathrm{Na}$ are common fingerprints of Antarctic open-system terrestrial weathering (Kurat et al. 1994; Van Ginneken et al. 2016). Depletions arise via leaching, while enrichments are products of secondary replacement, primarily through the growth of S- and K-bearing jarosite.

7 and TAM19B-7 were collected on cross section samples using a constant $\omega$ angle of $20^{\circ} 2 \theta$ and a rotating $\phi$ axis to maximize the number of crystallites and the randomness of their orientations in the X-ray beam. Low-angle $\left(<20^{\circ} 2 \theta\right)$ diffraction peaks could not be collected from TAM19-7 and TAM19B-7, because the polished resin block that holds these micrometeorites prevented the stage from rotating in the $\omega$ plane by $<20^{\circ} 2 \theta$. However, the full diffraction range $\left(5-85^{\circ} 2 \theta\right)$ was collected from TAM37P-03, because this micrometeorite was not embedded in a resin block at the time of XRD analysis and instead, was mounted on a carbon fiber, using araldite and subsequently attached to a brass pin that was placed on the goniometer head. The data from TAM37P-03 were collected with $\omega$ oscillating between -15 to $150^{\circ} 2 \theta$ and a continuously rotating $\phi$ axis. Despite the larger diffraction range, low-angle data collection did not reveal the presence of additional minerals. Phyllosilicates were not detected in any sample. Peak positions in the converted 1-D patterns were identified by comparison against a comprehensive mineral standards database (PDF-4 database from ICDD).

\section{Mid-IR Spectroscopy}

Mid-IR spectroscopic data were collected at Diamond Lightsource, located within the Harwell science and innovation campus in Didcot, Oxfordshire, UK. A
Thermo Scientific FT-IR spectrometer equipped with a Nicolet continuum microscope attachment was used to collect reflectance spectra from the polished surfaces of each micrometeorite (after removal of the carbon coating by polishing). The global micrometeorite spectra shown in this study were generated by integrating 120 scans, collected using a $100 \mu^{2}$ aperture and a spectral resolution of $4 \mathrm{~cm}^{-1}$. A reference background spectrum, collected upon a clean, polished gold standard, was subtracted from the raw data. Spectra were collected in air and corrections for atmospheric suppression were not applied. This is because atmospheric artefacts are not present within the region of interest $(\lambda=8-15 \mu \mathrm{m})$. No baseline correction was required; however, each spectrum (Fig. 2) is scaled and offset to aid visual comparison.

\section{Micro-Computed Tomography}

Within earth sciences, the use of noninvasive, highresolution $\mu \mathrm{CT}$ has found a wide range of applications visualizing the internal structure of small, rare, and complex materials (Ketcham and Carlson 2001; Landis and Keane 2010; Lin et al. 2016). In this study, we employed a laboratory-based Zeiss Xradia 510 Versa Xray microscope, located in the Earth Science and Engineering Department at Imperial College London to analyze TAM37P-03.

A total analysis volume of approximately $500 \times 500 \times 500 \mu \mathrm{m} \quad\left(0.125 \mathrm{~mm}^{3}\right)$ was investigated, 


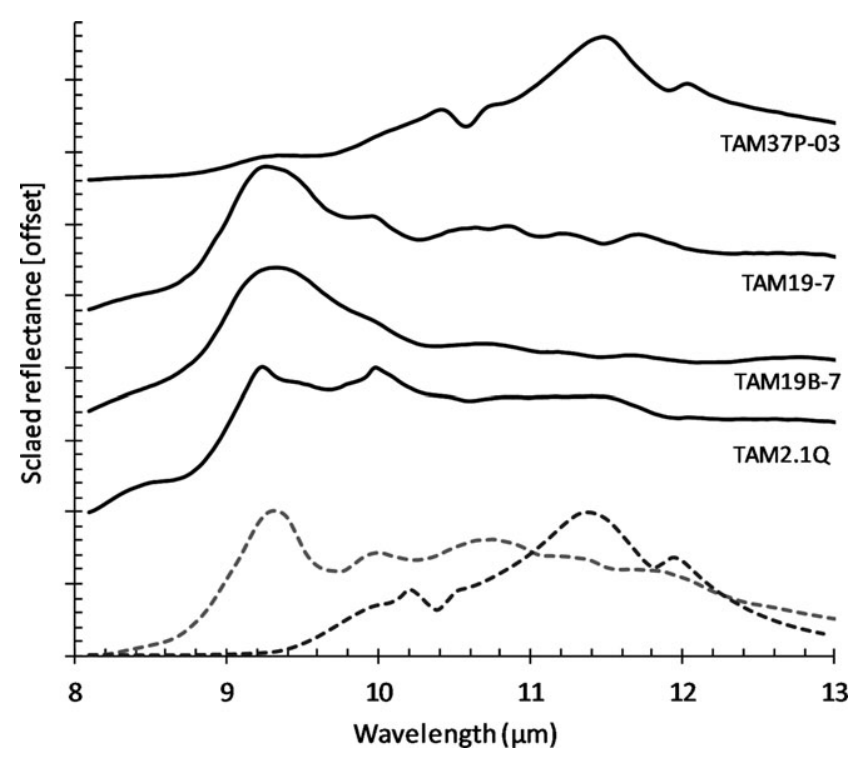

Fig. 2. Global mid-IR spectra for all four TAM micrometeorites. The selected spectral range $(8-13 \mu \mathrm{m})$ covers the silicate fingerprint region, providing information on the bulk mineralogy of a sample. TAM2.1Q contains two relatively sharp primary peaks, located at $\sim 9.0$ and $10.0 \mu \mathrm{m}$; these positions closely match the main peak positions in jarosite, a common terrestrial alteration product affecting TAM samples. Conversely, TAM19B-7 and TAM19-7 produce spectra similar to dehydroxylated saponite (heated to $700{ }^{\circ} \mathrm{C}$; see Che and Glotch 2012). These spectra are characterized by a smooth, wide primary peak, located at $\sim 9.0 \mu \mathrm{m}$, which reflects the excitation of isolated silica tetrahedra. Additional minor peaks at higher wavelengths are present. TAM37P-03 produces an olivine dominated spectra. Implying this micrometeorite has experienced recrystallization at temperatures close to $1350{ }^{\circ} \mathrm{C}$ (Suttle et al. 2017). Reference spectra for saponite and forsterite shown in light and dark gray, respectively, at the bottom of this chart.

which included the entire micrometeorite's volume $\left(\sim 0.04 \mathrm{~mm}^{3}\right)$. The sample was scanned using a cone-beam setup and sealed transmission X-ray source, at high energy $(50 \mathrm{keV})$ and with a $20 \times$ magnification lens. This generated a high-resolution scan, with a voxel size of just $0.64 \mu \mathrm{m}$. A 3-D model of the particle could then be created using the 871 tomographic slices-acquired at a rotation rate of $\sim 0.2^{\circ}$ per projection. Before processing these images, the raw reconstructed scan was filtered using a nonlocal means edge preserving filter (Buades et al. 2008) that reduced image noise arising from beam attenuation, beam hardening, and ring artefacts (Ketcham and Carlson 2001). Pore space within this micrometeorite was then segmented using a histogrambased thresholding method (Tsai 1985) as shown in Fig. S1 in supporting information. In the final data set (Fig. 3 and Fig. S2 in supporting information. [an.mp4 video file, showing all the tomographic slices]), darker regions represent void space, while grayscale values reflect the average atomic weight of the sample, with white areas representing the highest average weight materials.

\section{RESULTS}

\section{General Characteristics}

Each particle's bulk composition (Fig. 1; Table 2) is broadly chondritic (with major and minor element concentrations generally within one order of magnitude of CI values and never greater than two orders of magnitude). Three of the micrometeorites (TAM19-7, TAM19B-7, and TAM2.1Q) have very similar geochemical profiles with significant depletions, up to one order of magnitude below CI concentrations, observed for $\mathrm{P}$ and $\mathrm{Ni}(0.07-0.29$ and $0.05-1.00$, respectively), while their $\mathrm{Mg}$ and $\mathrm{Ca}$ concentrations are depleted by approximately half below CI Ivuna's concentration. In contrast, $\mathrm{Al}, \mathrm{Ti}, \mathrm{Na}$, and $\mathrm{K}$ are elevated above chondritic values. Most notably, $\mathrm{K}$ concentrations are elevated up to 100 times above chondritic values, translating to elemental abundances up to $2.76 \mathrm{wt} \%$. Elemental X-ray map data (Fig. 4C) reveal a close relationship between the distributions of $\mathrm{Na}, \mathrm{K}, \mathrm{Cl}$, and $\mathrm{S}$, which are also welldispersed throughout the particles. Using $\mu \mathrm{XRD}$ (Table 3; Fig. 5), jarosite $\left(\mathrm{KFe}^{3+}{ }_{3}[\mathrm{OH}]_{6}\left[\mathrm{SO}_{4}\right]_{2}\right)$ was identified in TAM19-7 and TAM19B-7 and is likely present in the remaining two particles. Conversely, the bulk geochemistry of TAM37P-03 is distinct. This particle has a mildly refractory enriched composition $(1<\mathrm{Al}, \mathrm{Ca}, \mathrm{Mg}$ and $\mathrm{Si}<20 \times \mathrm{CI}$ values $)$, with minor depletions in $\mathrm{Cr}$ and $\mathrm{Mn}(0.1<\mathrm{M}<1 \times \mathrm{CI}$ values $)$ and an elevated Fe concentration ( $\sim 30 \times \mathrm{CI}$ values).

The $\mu$ XRD pattern data provide information on a sample's bulk mineralogy. Anhydrous silicates (forsterite and enstatite) and magnetite $\left[\mathrm{Fe}_{3} \mathrm{O}_{4}\right]$ are common components, present both in the particle rims and dispersed throughout the micrometeorites (Figs. 3, 4, 6, and 7). Iron sulfides were also identified, troilite [FeS] was detected in TAM19-7, while akaganéite $\left[\mathrm{Fe}^{3+} \mathrm{O}\right.$ $(\mathrm{OH}, \mathrm{Cl})]$ was identified in TAM19B-7. Jarosite was the only other mineral identified. Additional minor and accessory minerals may also be present, which were not detected either due to low concentrations, or because these minerals were not within the X-ray beam during analysis. Furthermore, the relatively low mineral diversity could indicate the presence of amorphous phases within some particles, which could not be detected using $\mu \mathrm{XRD}$.

We also collected mid-IR spectra, which provide complementary data to the $\mu \mathrm{XRD}$, revealing the mineralogy of each sample. The spectra of TAM19-7 

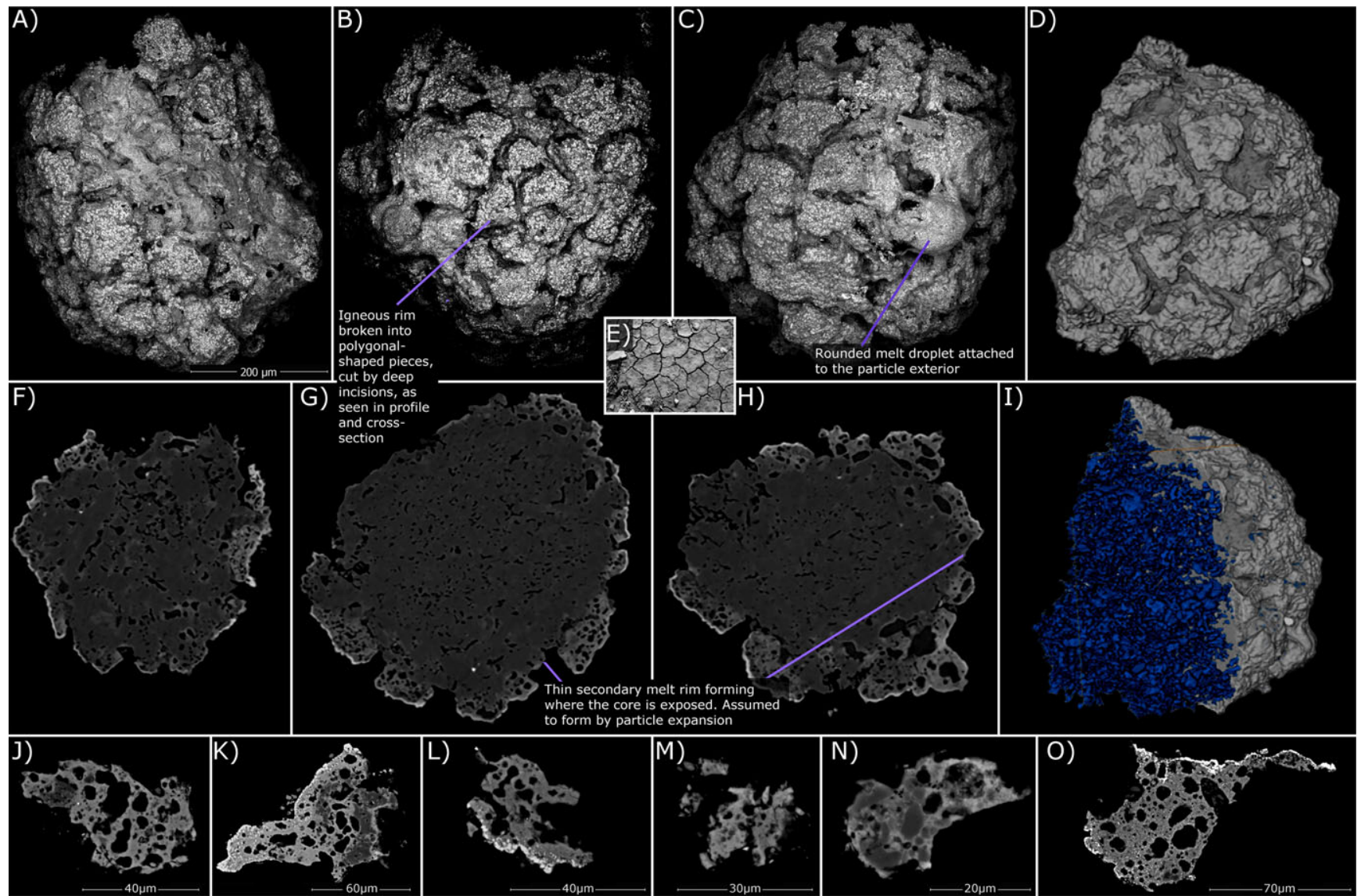

Fig. 3. TAM37P-03 analyzed under SEM-BEI and $\mu$ CT. A-C) External (uncoated) backscattered electron images in three different orientations are compared against (D) the computer-generated 3-D model of this micrometeorite built from $871 \mu \mathrm{CT}$ scans. This micrometeorite contains a well-developed, paired magnetite and igneous rim that form an unusual outer crust, composed of polygonal raised plateaus, isolated from each other by deep incisions. The particle's crust is, therefore, superficially similar to (E) desiccation cracks formed on Earth as fine-grained muds dry in semiarid environments. $\mathrm{F}-\mathrm{H}$ ) Internal cross section images (tomographic slices) taken at three different depths within the micrometeorite, revealing that the particle core is unmelted, finegrained homogenous and appears Mg-rich (dark Z values). Dark inclusions representing anhydrous silicates, sulfides or oxides are absent. I) The 3-D micrometeorite model, generated using the $\mu \mathrm{CT}$ data, was evaluated to analyze pore space and permeability. To view the complete CT scan, see Fig. S2. J-O) This particle was then crushed and some fragments (including pieces of the igneous rim) were also embedded in resin and are shown here and found to contain $\mathrm{Mg}$-rich olivine relict grains.

Table 2. Micrometeorite bulk compositions determined by averaging multiple WD-EMPA spot analyses. Values marked with b.d.l. are below the detection limit threshold, while No. denotes the number of independent analyses which were averaged to generate the given results. Elements are ordered in increasing volatility and data from CI Ivuna are also included in this table and employed as reference values in the spider plot (Fig. 1).

\begin{tabular}{lllllllllllllllll}
\hline Particle & No. & $\mathrm{Al}$ & $\mathrm{Ti}$ & $\mathrm{Ca}$ & $\mathrm{Mg}$ & $\mathrm{Si}$ & $\mathrm{Cr}$ & $\mathrm{Mn}$ & $\mathrm{Fe}$ & $\mathrm{Ni}$ & $\mathrm{Na}$ & $\mathrm{K}$ & $\mathrm{P}$ & $\mathrm{S}$ & $\mathrm{O}$ & Total \\
\hline TAM19B-7 & 20 & 1.9 & b.d.1. & 0.1 & 2.1 & 17.7 & 0.6 & b.d.1. & 21.9 & 0.4 & 0.4 & 0.4 & 0.2 & 2.4 & 36.8 & 84.9 \\
TAM19-7 & 19 & 2.0 & 0.1 & 0.1 & 5.9 & 19.7 & 0.4 & 0.1 & 18.3 & 0.2 & 0.7 & 1.2 & b.d.1. & 3.3 & 39.2 & 91.2 \\
TAM2.1Q & 15 & 4.7 & 0.3 & 0.3 & 3.1 & 10.3 & 0.2 & 0.1 & 26.5 & 0.1 & 0.4 & 2.8 & 0.1 & 5.5 & 34.9 & 89.3 \\
TAM37P-03 & 24 & 2.6 & b.d.1. & 1.6 & 13.1 & 16.1 & 0.3 & 0.1 & 22.5 & 1.1 & 0.1 & b.d.1. & b.d.1. & 0.2 & 37.3 & 95.0 \\
CI Ivuna & 34 & 1.1 & b.d.1. & 0.4 & 12.2 & 14.8 & 0.3 & 0.1 & 15.3 & 1.5 & 0.3 & b.d.1. & 0.2 & 2.8 & 35.6 & 84.6 \\
\hline
\end{tabular}

and TAM19B-7 (Fig. 2) are characterized by a broad primary peak centered between $\sim 9.0$ and $9.5 \mu \mathrm{m}$. Additional minor peaks at higher wavelengths are also present. The broad shape of these peaks indicates a lack of long-range order and, therefore, a low degree of crystallinity (Speck et al. 2011), while the position of 

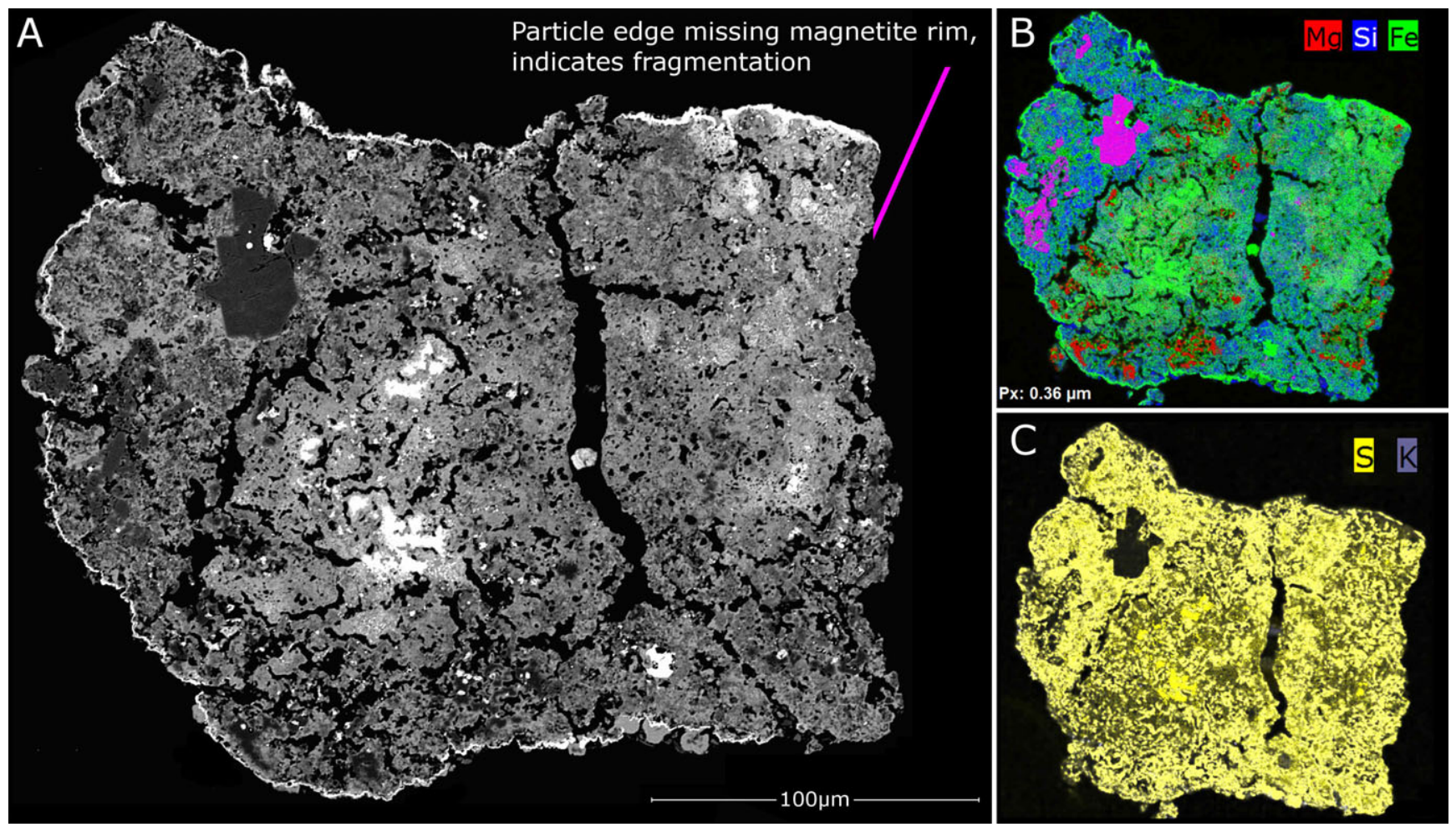

Fig. 4. A) Backscattered electron image of TAM2.1Q. This micrometeorite contains an incomplete magnetite rim that encloses three sides of the approximately rectangular cross section. The single side missing a magnetite rim also contains an angular morphology, suggesting minimal entry heating and no melting. This grain edge most likely represents where the particle fragmented during terrestrial residence or collection. B) The particle interior is dominated by angular forsterite grains (shown in purple), containing poikilitic Fe-Ni droplets and Fe-sulfides (shown in green) sitting within a fine-grained matrix. Several large channels cut this micrometeorite almost completely along the particle's width. C) Long residence times, held in Antarctic rock traps, have resulted in replacement by jarosite, which appears to affect the entire particle except for the anhydrous silicates that appear black in the combined $\mathrm{S}$ and $\mathrm{K}$ element map.

Table 3. Micrometeorite mineralogy determined using $\mu$ XRD. Particles TAM19-7 and TAM19B-7 were embedded in epoxy resin, restricting data collection to the exposed cross section surfaces, while TAM37P-03 was analyzed as a grain mount; this allowed a greater range of reflection angles to be collected. Solid black circles mark detected minerals while the open circles (for TAM19B-7) indicate the suspected former presence of troilite and pyrrhotite, which were altered to akaganéite during terrestrial weathering. Secondary weathering minerals are marked in light gray.

\begin{tabular}{llllllll}
\hline Sample & Forsterite & Enstatite & Magnetite & Troilite & Pyrrhotite & Jarosite & Akaganéite \\
\hline TAM19-7 & $\bullet$ & $\bullet$ & $\bullet$ & $\bullet$ & & $\bullet$ & \\
TAM19B-7 & $\bullet$ & & $\bullet$ & 0 & 0 & $\bullet$ \\
TAM37P-03 & $\bullet$ & $\cdot$ & $\cdot$ & & & \\
\hline
\end{tabular}

the primary peaks is attributed to residual $\mathrm{SiO}_{4}$ tetrahedra (Speck et al. 2011). These spectral profiles bear close resemblance to amorphous, dehydroxylated phyllosilicates shown in Che and Glotch (2012 [saponite at $700{ }^{\circ} \mathrm{C}$ seen in Fig. 3]) and Fig. 9 of Suttle et al. [2017]) and implies that TAM19-7 and TAM19B-7 are composed primarily of amorphous and poorly crystallized silicate phases, formed after the thermal decomposition of phyllosilicate. Conversely, the spectra of TAM37P-03 are identical to that of crystalline olivine, which is consistent with the particle's bulk mineralogy as determined by $\mu$ XRD. In contrast, the spectrum of TAM2.1Q is distinct and dominated by sulfate phases. Reflectance rises sharply with increasing wavelength from the Christiansen minimum located at $\sim 7.5 \mu \mathrm{m}$. (The Christiansen minimum, which for silicate minerals occurs at wavelengths between 6 and $9 \mu \mathrm{m}$, represents where the refractive index of the sample and the air is equal. This 


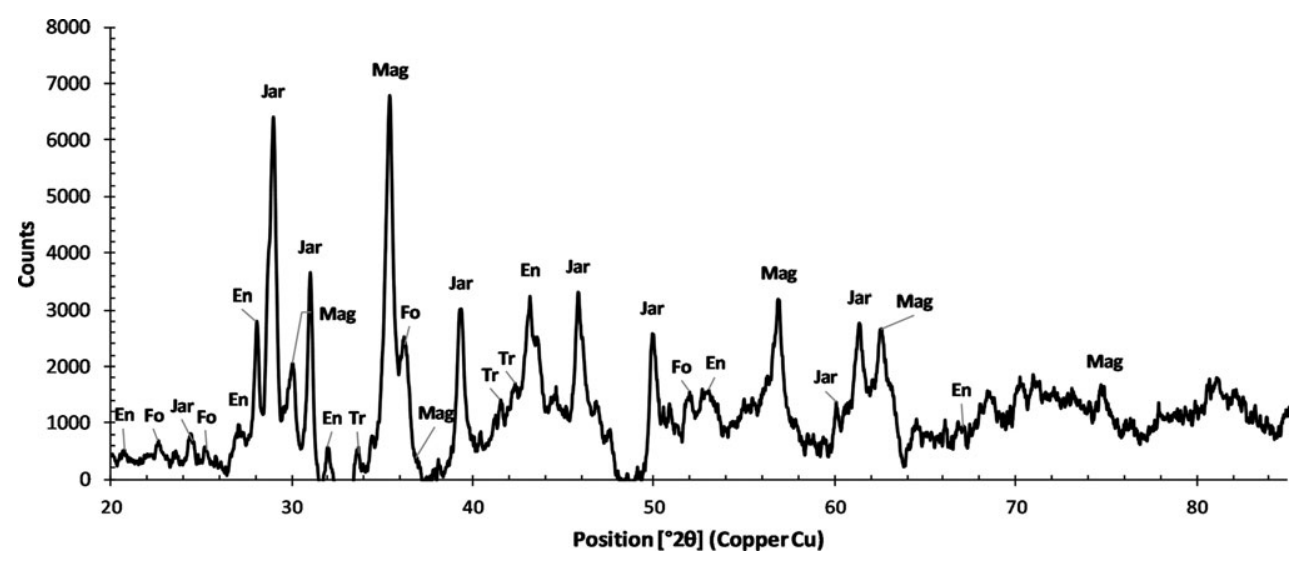

Fig. 5. An example $\mu$ XRD pattern (TAM19-7). Diffraction angles over the range $20-85^{\circ} 2 \theta$ were collected. Lower angle reflections could not be obtained owing to limitations in the experimental setup. All peaks are assigned, and several major peaks are labeled as: forsterite (Fo), enstatite (En), trolite ( $\mathrm{Tr}$ ), magnetite (Mag), and jarosite (Jar). Reflection peaks are relatively broad compared to mineral standards implying a low degree of crystallinity.
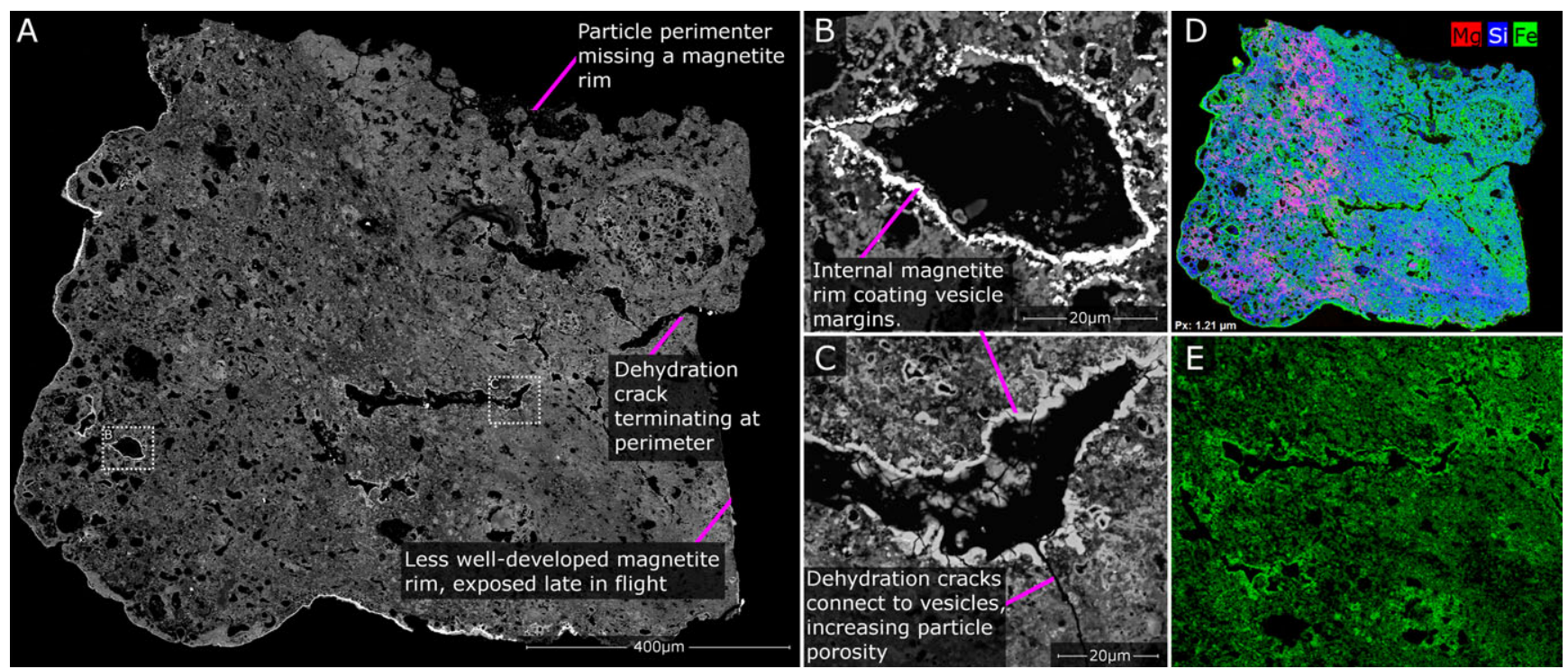

Fig. 6. A) Backscattered electron image of TAM-19B-7. This micrometeorite consists of fine-grained matrix mantled by a paired igneous and magnetite rim. Abundant void space is present in the form of dehydration cracks and vesicles. Magnified images highlight (B) a large vesicle, surrounded by an internal magnetite rim, one of many found within this micrometeorite and (C) a large channel, composed of interconnected secondary pore space that developed during atmospheric entry heating, as a result of volatile gas production. D) The major element map ( $\mathrm{Mg}, \mathrm{Si}, \mathrm{Fe})$ demonstrates that this micrometeorite is separated into two geochemically distinct domains, the upper right being composed of Fe-rich (Mg-poor) matrix, while the lower left portion contains higher $\mathrm{Mg}$ concentrations. Fe enrichment is observed adjacent to channels and forms magnetite rims along channel walls. E) An Fe-element distribution map also reveals Fe enrichment in matrix sections in close proximity to secondary pore space; this is taken as evidence of enhanced gas-driven heating.

feature is diagnostic for inorganic minerals and is, therefore, a critical tool in mid-IR spectroscopy [Salisbury and Wald 1992]). Two primary peaks centered at approximately $9.2 \mu \mathrm{m}$ and $10.0 \mu \mathrm{m}$ are the only major IR-active bands. A local reflectance minimum is located at $10.6 \mu \mathrm{m}$ and followed by a reflectance plateau between 10.8 and $11.5 \mu \mathrm{m}$, which drops to a secondary plateau at $11.9 \mu \mathrm{m}$. The location of the primary peaks and Christiansen minimum in TAM2.1Q closely match the position of the IR-active bands in jarosite (Baldridge et al. 2009), suggesting that TAM2.1Q is dominated by sulfates. However, this mineral standard alone is an imperfect match and, therefore, either additional minerals are present, or the grain size of the standard is different to that of the sample.

All four micrometeorites contain well-developed but incomplete magnetite rims, which encircle the particle exterior and vary in thicknesses between $1 \mu \mathrm{m}$ and $15 \mu \mathrm{m}$. 

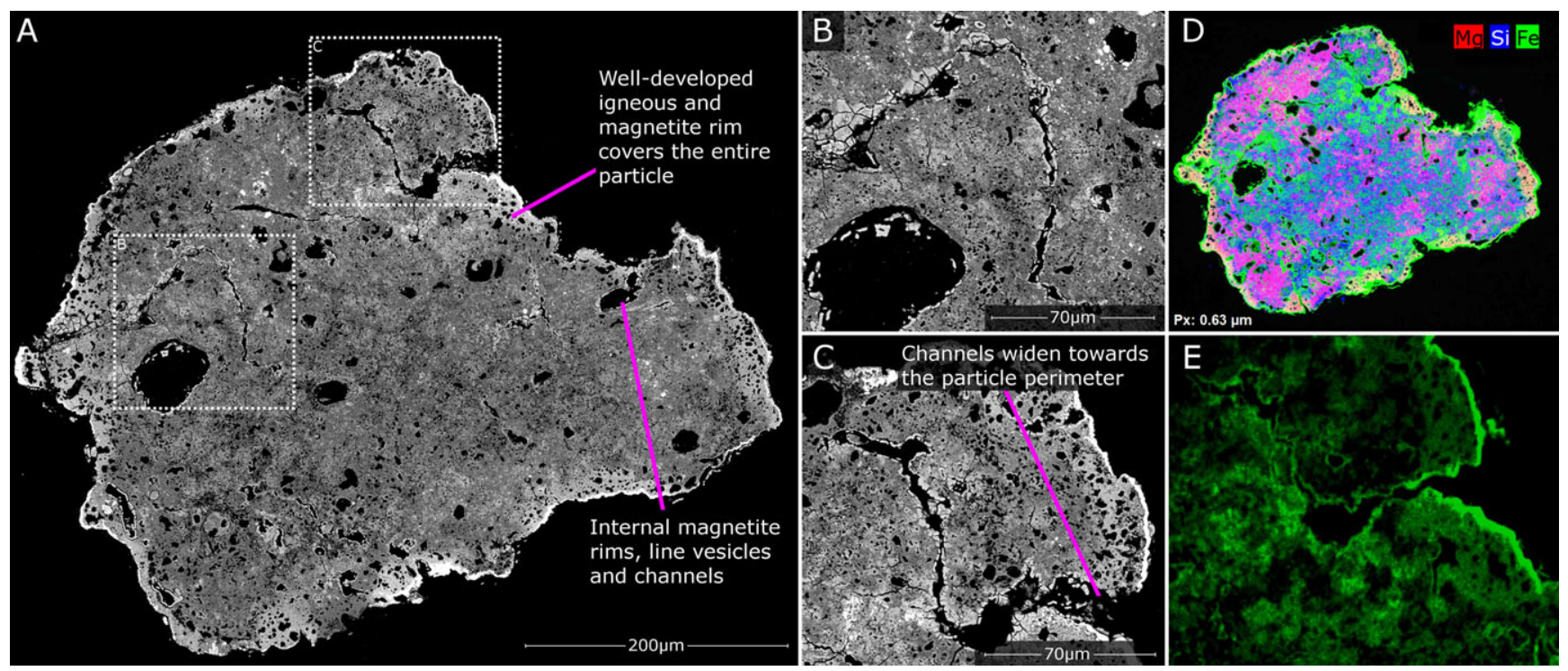

Fig. 7. A) Backscattered electron image of TAM19-7. This micrometeorite contains a complete and well-developed igneous and magnetite rim. The interior mineralogy is composed of mixed dehydroxylated phyllosilicates and micron-scale, recrystalized olivine and pyroxene. Accessory platelet and framboidal magnetite are also present. The internal texture is dominated by a matrix rich in vesicles and contains four prominent channels that connect the particle perimeter to the core. Two channels are shown in magnified view B (and E) and (C). D) The major element map illustrates how secondary pore space channels, notably the channel displayed in (c), can result in enhanced thermal processing of adjacent matrix, leading to Fe enrichment; this is also shown in (E) the single element Fe-map. These observations support the suggestion of gas-driven heating during atmospheric entry.

Igneous rims are found in close association with magnetite rims and vary in thickness between $5 \mu \mathrm{m}$ and $50 \mu \mathrm{m}$. For all micrometeorites, the particle matrix is homogeneous on $>10 \mu \mathrm{m}$ length scales and contains significant pore space, either in the form of small $(<20 \mu \mathrm{m})$ isolated, circular or elongated voids or as long channels (typically $>100 \mu \mathrm{m}$, Figs. 4, 6, and 7). These channels are composed of interconnected networks of thin cracks and rounded, broadly circular voids. Channels reach up to $300 \mu \mathrm{m}$ in length and typically have winding and branching (dendritic) profiles. Several channels terminate at the particle's perimeter (Fig. 7C), and although widths are variable (typically $<5-30 \mu \mathrm{m}$ ), in general, channels narrow toward the particle core. Several large voids and most channels contain Fe-rich linings $(<5 \mu \mathrm{m}$ thick), which in TAM19B-7 are composed of magnetite, while in TAM197 they are composed of a nonstoichiometric Fe-oxide phase, with atomic $\mathrm{O} / \mathrm{Fe}$ ratios between three and five. Disseminated Fe-Ni sulfides (troilite and pyrrhotite) and reduced $\mathrm{Fe}-\mathrm{Ni}$ metal are also present in all particles, though these phases tend to be concentrated near the particle center or found in association with vesicles, as is reported in Taylor et al. (2011).

\section{TAM19B-7}

The particle's exposed cross section (Fig. 6) is broadly rectangular with dimensions of approximately
$830 \times 950 \mu \mathrm{m}$ and, therefore, represents the largest finegrained micrometeorite currently documented. One side of the micrometeorite cross section completely lacks a magnetite rim, and instead, contains an angular and reentrant morphology. Two external surfaces of the particle (left and bottom edges in Fig. 6) are lobate and rounded on scales of $100 \mu \mathrm{m}$ and support a $10-35 \mu \mathrm{m}$ thick igneous rim. The third external surface (the right edge of the micrometeorite in Fig. 6) has a straight segment that runs approximately two-thirds of the particle's length and terminates at a surface whose orientation is controlled by an internal cavity. The straight surface has a partial magnetite rim but no igneous rim. Finally, the upper surface (as seen in Fig. 6) has an irregular shape and completely lacks an igneous or magnetite rim.

The internal porosity of this micrometeorite is high; an approximation achieved by analyzing the percentage of voids in the exposed 2-D cross section, suggests a porosity of $\sim 18 \%$. This is composed primarily of large interconnected channels and rounded vesicles, two of which are highlighted in Figs. 6B and 6C. Most of these voids contain internal magnetite rims and show a pronounced $\mathrm{Fe}$ enrichment in the matrix adjacent to voids (Figs. 6D and 6E). Channels vary in morphology from straight to curved cavities with re-entrant margins at smaller scales (Fig. 6C). Channels vary in width from $<1$ to $\sim 40 \mu \mathrm{m}$ and reach up to $300 \mu \mathrm{m}$ in length. Two of the larger channels bifurcate, creating Y-shaped voids. 


\section{TAM19-7}

This large micrometeorite (Fig. 7A, $410 \times 530 \mu \mathrm{m}$ ) contains a geochemically homogenous matrix, showing moderate variation in major element $\mathrm{Fe}$ and $\mathrm{Mg}$ concentrations across the particle (Fig. 7E). Small $(<10 \mu \mathrm{m})$ disseminated Fe-sulfides, in the form of troilite and, less commonly, pyrrhotite are present, as well as anhedral, framboidal, and platelet magnetite clusters. Both magnetite and sulfides are commonly adjacent to or surrounded by vesicles. The mid-IR spectra of TAM19-7 is characterized by an amorphous dehydroxylated phyllosilicate signature, indicating the former presence of hydrated sheet silicates. However, because the $\mu$ XRD data cannot discriminate contributions from amorphous phases, only anhydrous forsterite and enstatite were detected. Since large individual anhydrous grains are not seen under BEI, these minerals must be present as a microcrystalline groundmass, intermixed with the amorphous material. Jarosite is also detected by $\mu \mathrm{XRD}$.

An igneous rim on TAM19-7 is well developed and reaches a thickness of $\sim 30 \mu \mathrm{m}$. This consists of micron-scale equant olivine crystals embedded in glass and with vesicular texture, thus the igneous rim on TAM19-7 is consistent with those described by Genge (2006) from smaller fine-grained micrometeorites. In addition, the igneous rim penetrates inwards, following the margin of the two largest cavities (Figs. 7B and 7C). Here these large cavities vary from 1 to $15 \mu \mathrm{m}$ in width, approach $300 \mu \mathrm{m}$ in length, and include both curved and straight segments with re-entrant margins and $\mathrm{Fe}$-oxides linings.

\section{TAM2.1Q}

This is the smallest of the four micrometeorites at $200 \times 280 \mu \mathrm{m}$ (Fig. 4A). This particle has an incomplete magnetite rim that is present on three sides of the particle. The geochemistry and mineralogy of this micrometeorite is dominated by jarosite, as demonstrated by both the mid-IR spectrum (Fig. 2) and the combined K-S element map (Fig. 4C). However, matrix-hosted forsteritic olivines are also present, and reach up to $25 \mu \mathrm{m} \times 50 \mu \mathrm{m}$ in size; several grains also contain $\mathrm{Fe}-\mathrm{Ni}$ metal droplets. TAM2.1Q contains large voids in the form of channels, notably a single channel runs almost the entire particle length $(156 \mu \mathrm{m})$ and reaches up to $10 \mu \mathrm{m}$ in width. As with TAM19-7, these channels often bifurcate.

\section{TAM37P-03}

This micrometeorite has a total volume of $\sim 0.1 \mathrm{~mm}^{3}$ and dimensions of $\sim 450 \times 460 \times 520 \mu \mathrm{m}$. TAM $37 \mathrm{P}-03$ was selected for study owing to its large size and because its outer crust is unusual-unlike any unmelted micrometeorites that we have previously studied. A welldeveloped, igneous and magnetite rim surrounds the entire particle (Figs. 3A-D). However, this rim is unusually thick, reaching up to $100 \mu \mathrm{m}$ in places. This contrasts with the typical igneous rim found on small Antarctic micrometeorites, which are commonly $<20 \mu \mathrm{m}$ thick (as shown in Fig. 8) (Genge 2006). In TAM37P-03, most of the particle's outer surface is broken into a series of raised, polygonal-shaped plateaus that are separated by deep and steep-sided incisions (between 20 and $100 \mu \mathrm{m}$ deep). As a result, we describe this crust as "fissure-textured" and note that it closely resembles both the texture of desiccation cracks, found in semiarid environments (Fig. 3E) (El Maarry et al. 2012) and the fusion crusts of $\mathrm{CM}, \mathrm{CV}$, and $\mathrm{CO}$ carbonaceous chondrites (Genge and Grady 1998). In several places, the fissure texture is interrupted by smooth, bulbous areas of igneous rim, interpreted as crystalized droplets of chondritic melt (Fig. 3C).

The micrometeorite core (Figs. 3E-G and Fig. S2) is unmelted, homogenous, and appears dark in the CT tomographic slices. Since darker shades represent lower average atomic weights, this implies that the core of TAM37P-03 is Mg-rich. We subsequently crushed this particle and analyzed 19 small $(<60 \mu \mathrm{m})$ fragments, using standard-based EDS, intending to save the majority of the particle's mass for future destructive (O-isotope) analyses. However, several fragments were also analyzed under the SEM, with most of these being derived from the outermost layer of this micrometeorite and are, therefore, composed of fine-grained matrix. These fragments reveal average $\mathrm{Mg}$ concentrations of $13.1 \mathrm{wt} \%$ ( $\sim 10 \mathrm{wt} \%$ higher than the other three TAM particles) and a particle texture composed of fine-grained relatively $\mathrm{Fe}-$ enriched matrix (Mg\#24.7-69.7, with an average of $\mathrm{Mg \# 56.3)} \mathrm{hosting} \mathrm{an} \mathrm{abundance} \mathrm{of} \mathrm{small}(<30 \mu \mathrm{m})$ relict high-Mg forsterite grains with compositions ranging from Fo\#76.8 to Fo\#98.9, but averaging values of Fo\#93.7 (Figs. $3 \mathrm{~K}$ and $3 \mathrm{~N}$ ). These olivine crystals have minor trace element contents $\left(\mathrm{Al}_{2} \mathrm{O}_{3}[0.5-4.2 \mathrm{wt} \%], \mathrm{CaO}[0.6-2.0\right.$ $\mathrm{wt} \%$ ], $\mathrm{Cr}_{2} \mathrm{O}_{5}$ [0.6-1.0 wt\%], $\mathrm{MnO}[<0.4 \mathrm{wt} \%$ ], and $\mathrm{NiO}$ $[<0.6 \mathrm{wt} \%])$, which are consistent with the trace element compositions of forsterite found in primitive unmelted micrometeorites and $\mathrm{C} 2$ carbonaceous chondrites (Steele 1992; Imae et al. 2013). Because we did not directly image the particle core under SEM-BSE, its internal texture and mineralogy must be inferred from the $\mu \mathrm{CT}$ data. This suggests that TAM37P-03 is a composite micrometeorite, containing a compact polycrystalline core composed of many relatively large anhydrous forsterite grains $(>60 \mu \mathrm{m})$ with irregular and interlocking shapes. This core is surrounded by a $>100 \mu \mathrm{m}$ mantle of fine-grained and 

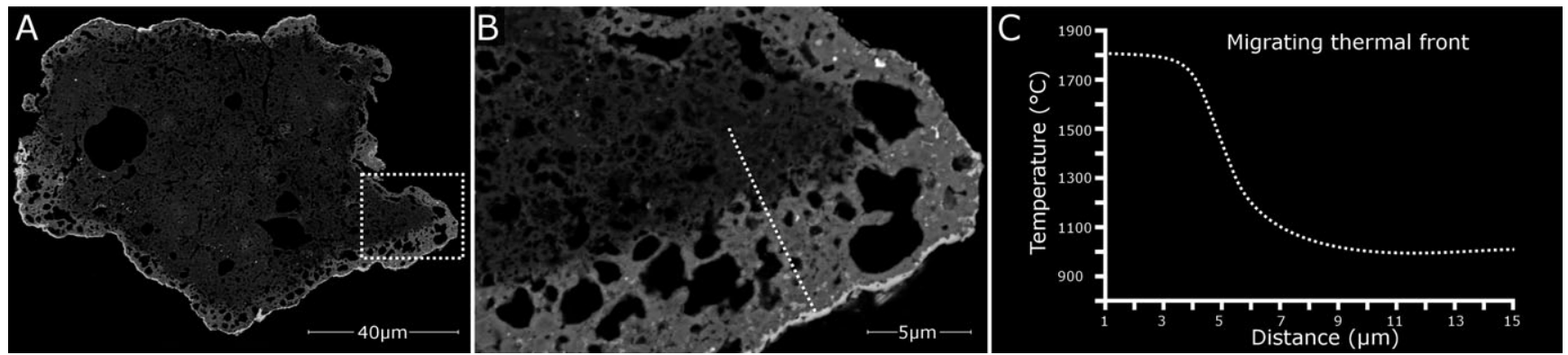

Fig. 8. A) A small Antarctic micrometeorite from Cap Prud'homme collection (CP94-050-054 published in Genge [2006]; Suttle et al. 2017). This micrometeorite contains a well-developed igneous rim with an approximate thickness of $7 \mu \mathrm{m}$ (B). The boundary between the igneous rim and the less heated core is a sudden sharp contact. C) Modeling from Genge et al. (2017) suggests that igneous rims like these require high thermal gradients $\left(>200 \mu \mathrm{m} \mathrm{K}{ }^{-1}\right)$ and arise only where hydrated phyllosilicates thermally decomposed and then melt, providing a sink to absorb the abundant heat energy generated during atmospheric entry. As a result, hydrated particles can maintain relatively low internal temperatures $\left(\sim 600-1100{ }^{\circ} \mathrm{C}\right.$; Suttle et al. 2017) and consequently preserve unmelted and dehydroxylated phyllosilicates or recrystalized anhydrous olivine at their core. This study suggests that core-to-rim thermal gradients maintained by thermal conduction are overprinted in larger particles once secondary pore space and branching channels develop.

relatively Fe-rich matrix that contains regions which completely melted to form the scoriaceous-textured igneous rim; thus, TAM37P-03 may represent a chondrule and surrounding fine-grained matrix, derived from a hydrated phyllosilicate-bearing $\mathrm{C} 2$ parent body such as a CM or CR chondrite (Genge et al. 2005, 2008).

TAM37P-03 also has a high porosity. Using data obtained from the pore segmentation routine, extracted from the CT scan (Fig. S1 and Fig. 3H), TAM37P-03 has an apparent porosity of $12.9 \%$. Sixty-four percent of pore space volume (or $8.2 \%$ of the micrometeorite's total volume) are interconnected and link to the particle exterior.

\section{DISCUSSION}

\section{Terrestrial Weathering in Antarctic Environments}

Antarctic micrometeorites from the TAM collection may spend on the order of $10^{2}-10^{6}$ years at the Earth's surface, trapped in ice, snow, or as loose grains among terrestrial sediments (Taylor et al. 2000; Rochette et al. 2008; Suavet et al. 2009). During this time, they are likely to pass through multiple freeze-thaw cycles as temperatures fluctuate around $0{ }^{\circ} \mathrm{C}$, particularly through the summer months (LaPrade 1986; Van Ginneken et al. 2016). Here, contact with liquid water results in slow chemical attack. The weathering of micrometeorites from the TAM collection has been studied in detail by Van Ginneken et al. (2016) and currently represents the only dedicated investigation of this type. As such, the distinctive weathering profiles, textures, and mineralogy of the TAM micrometeorites is well-documented.

Terrestrial alteration progresses via several different mechanisms, i.e., (1) mobile elements are leached from minerals, which explains the observed depletions in $\mathrm{P}, \mathrm{Ni}$,
$\mathrm{Co}, \mathrm{Mg}$, and $\mathrm{Ca}$ that affect the three particles (TAM19-7, TAM19B-7, and TAM2.1Q) studied here (Fig. 1; Table 2). (2) Low crystallinity phases, such as silicate glass and amorphous dehydroxylates, are highly susceptible to dissolution. With longer durations, anhydrous silicates are progressively etched, forming residual crystals clusters. The resulting voids may then be (3) infilled by secondary minerals which precipitate from solution. The most common secondary mineral found in (and encrusting) the TAM micrometeorites is jarosite (Van Ginneken et al. 2016). This was identified in three of the four particles studied here. Jarosite forms where silicate minerals break-down under low-temperature acidic conditions and in the presence of sulfides (Hallis 2013). However, other common secondary minerals found among the TAM collection include palagonite, limonite, goethite, halite, calcite, and akaganéite (Van Ginneken et al. 2016). Here, we identified akaganéite in TAM19B-7 (Table 3). This is notable because it implies the former existence of extraterrestrial $\mathrm{Fe}-\mathrm{Ni}$ metal (most probably kamacite) and $\mathrm{Fe}-\mathrm{Ni}$ sulfides - most probably troilite and pyrrhotite $\left[\mathrm{Fe}_{(1-X)} \mathrm{S}_{X}\right]$. Akaganéite is a $\mathrm{Cl}$ bearing Fe-oxy-hydroxide mineral, commonly found in weathered Antarctic meteorites (Bland et al. 1997). Similarly, the internal channels described in TAM19-7 were also found to have Fe-rich linings with a nonstoichiometric composition and atomic $\mathrm{O} / \mathrm{Fe}$ ratios between three and five. This implies a mixed mineral assemblage, composed of Fe-hydroxides and oxyhydroxides that we interpret as limonite growths after magnetite. Magnetite is the most likely precursor mineral because unaltered magnetite was found lining the channels in TAM19B-7.

The least altered micrometeorite is TAM37P-03, whose bulk composition (Fig. 1) shows none of the 
typical depletions and enrichments described above. For example, this particle retains high concentrations of $\mathrm{Ni}$ $(1.1 \mathrm{wt} \%), \mathrm{Mg}(13.1 \mathrm{wt} \%)$, and $\mathrm{Ca}(\sim 1.6 \mathrm{wt} \%)$, which are otherwise depleted (relative to Ivuna) in the remaining micrometeorites. In addition, the SEM and $\mu \mathrm{CT}$ scans show no evidence of secondary mineral growth either as encrustations or replacement textures. This lower degree of terrestrial weathering implies a significantly shorter terrestrial residence time and could explain much of the disparity between the bulk composition of this particle and the remaining three micrometeorites.

Despite their terrestrial weathering overprints described above, the four micrometeorites in this study retain much of their atmospheric and extraterrestrial petrography, allowing their textures and mineralogy generated during atmospheric entry to be studied.

\section{Using Mid-IR Spectroscopy to Infer Peak Temperatures}

Previously, Suttle et al. (2017) investigated how the mineralogy of fine-grained micrometeorite matrix evolves during atmospheric entry, using mid-IR spectroscopy to reveal solid-state changes that occur prior to melting. They showed that micrometeorites follow a "standard model," which begins by the dehydration and subsequent dehydroxylation of phyllosilicates. Once structural water is lost from phyllosilicates, at temperatures between 300 and $700{ }^{\circ} \mathrm{C}$, these minerals break down into amorphous dehydroxylates. Further heating at temperatures between 700 and $1200{ }^{\circ} \mathrm{C}$ results in complete recrystallization of the matrix as crystalline olivine. Thus, the mid-IR spectra of three of the micrometeorites analyzed here follow this progression; with TAM19-7 and TAM19B-7 being composed primarily of amorphous phases (sustaining temperatures $<800{ }^{\circ} \mathrm{C}$ ), while TAM37P-03 has sustained higher temperatures and its matrix has recrystalized as an olivine groundmass $\left(<1200{ }^{\circ} \mathrm{C}\right)$. Conversely, the IR spectra of TAM2.1Q is dominated by sulfates, implying that its mineralogy has been replaced, almost entirely, by terrestrial weathering products, it is therefore not possible to accurately determine the likely peak temperature this particle sustained during entry. However, since the particle is unmelted, by definition, it must have experienced temperatures below the solidus of chondritic matrix $\left(\sim 1350{ }^{\circ} \mathrm{C}\right.$; Toppani et al. 2001).

The conclusion that TAM37P-03 experienced higher temperatures than either TAM19-7 or TAM19B-7 is consistent with its bulk geochemistry, which shows enriched concentrations of refractory $(\mathrm{Ca}, \mathrm{Al}, \mathrm{Ti})$ and moderately refractory $(\mathrm{Mg}, \mathrm{Si}, \mathrm{Ni}, \mathrm{Cr})$ elements. However, we also note that since TAM 37P-03 has less evidence of terrestrial weathering it is also likely that some enrichments (such as $\mathrm{Ni}$ and $\mathrm{Mg}$ ) may simply be because this particle has not experienced significant leaching by terrestrial water. Nevertheless, the four micrometeorites investigated in this paper span a range of peak temperatures $>400{ }^{\circ} \mathrm{C}$ and $<1350{ }^{\circ} \mathrm{C}$, which allows us to explore how their thermal decomposition and release of volatile gases affected the survival the micrometeorite matrix.

Although the four micrometeorites analyzed are classified as "unmelted" they have experienced small degrees of partial melting, both as melt layers on the particle perimeters-forming characteristic igneous and magnetite rims - and also locally within their cores, resulting in vesicles and zones of scoriaceous matrix. This requires that their heating was not uniform and, therefore, that thermal gradients existed within these micrometeorites. The origin and mechanism which maintains these gradients is explored below.

\section{Atmospheric Entry Heating in Large Micrometeorites}

In this study, the three giant fine-grained micrometeorites (TAM19-7, TAM19B-7, and TAM2.1Q) were found to contain large, relatively wide $(<3-40 \mu \mathrm{m})$ channels. These channels vary significantly, the largest tend to taper inwards toward the particle center and are, therefore, widest at the particle margin while some have relatively equal widths along most of their length. Several larger channels also bifurcate producing a branching network of passages. Furthermore, some channels are visibly connected to the particle exterior and exceed $300 \mu \mathrm{m}$ in length (Figs. 4 and 7). The origin of these channels is likely to be principally due to contraction of the matrix during dehydration reactions within phyllosilicate minerals (Noguchi et al. 2002; Nozaki et al. 2006; Che and Glotch 2012). This is because similar dehydration cracks are present in the thermally altered substrate beneath the fusion crust of meteorites (Genge and Grady 1998) and clearly form during entry heating in micrometeorites. However, crack growth and subsequent widening, developing into interconnected channels, is likely driven by the subsequent expansion of volatile gases. This is supported by the presence of rounded and isolated cavities that are also found within the TAM micrometeorites and form sections of the channels. Genge et al. (1997) described similar cavities and suggested that they are vesicles formed by the expansion of gases within the matrix. Thus, the large, branching channels described here appear to be composed of both linear dehydration cracks and rounded vesicles and formed during atmospheric entry heating.

During atmospheric entry, several chondritic phases are responsible for volatile release, including: phyllosilicates, sulfides, carbonates, and organic matter. The temperature range over which volatile production occurs is also significant, spanning at least $1000{ }^{\circ} \mathrm{C}$ (Genge 
et al. 1997; Greshake et al. 1998; Taylor et al. 2011; Court and Tan 2016). At the low temperatures $\left(<550{ }^{\circ} \mathrm{C}\right)$, carbonaceous and organic phases decompose, releasing $\mathrm{CH}_{4}, \mathrm{CO}_{2}$, and $\mathrm{H}_{2} \mathrm{O}$ (Glavin and Bada 2001). Later, phyllosilicates decompose between 300 and $800{ }^{\circ} \mathrm{C}$, releasing significant $\mathrm{H}_{2} \mathrm{O}$ in the form of vapor (Greshake et al. 1998; Genge 2006; Che and Glotch 2012). At progressively higher temperatures $\left(\sim 800-1100{ }^{\circ} \mathrm{C}\right)$, sulfides thermally decompose, producing $\mathrm{SO}_{2}$ and $\mathrm{SO}_{3}$ (Taylor et al. 2011). Above $900{ }^{\circ} \mathrm{C}$, carbonates break down, also releasing $\mathrm{CO}_{2}$ (Greshake et al. 1998). Furthermore, recent experimental heating of micrometeorite simulants also demonstrated the importance of secondary gas interactions. Most significantly, the carbothermic decomposition of organic matter, which results in the enhanced production of volatile gases by lowering the thermal decomposition threshold at which sulfides break down (Court and Tan 2016). Finally, Genge (2016) calculated that by the onset of melting, micrometeorites have lost $>99.9 \%$ of the volatile gas content. Given this complex array of reactions over a sustained temperature range and the large volumes of gases released, the production of volatiles and their subsequent heating of the particle's matrix is, evidently, an important process operating in micrometeoroids.

Within the core of a micrometeorite, during entry heating, absorbed water is lost from phyllosilicate interlayers in dehydration reactions. This causes contraction of the sheet silicates and the development of cracks (Shen et al. 1990; Nozaki et al. 2006). Experimental dehydration of phyllosilicates has previously demonstrated that volume losses between 20 and $30 \%$ are common (Esser 1990). With continued heating, structural water is also lost from $\mathrm{OH}$-bearing octahedral sheets through dehydroxylation reactions (Bray and Redfern 1999; Che and Glotch 2012). Dehydration cracks form parallel to the [001] axis of their phyllosilicate hosts (Nozaki et al. 2006) and progressively grow in length while also expanding in width (Shen et al. 1990) leading to the development of interconnections. Likewise, vesicles form by the release of volatile gases in heated micrometeorites (Taylor et al. 2011). It therefore seems probable that small dehydration cracks are the precursors to most vesicles.

In addition, most fine-grained unmelted micrometeorites contain zoned profiles (Figs. 8A and 8B), defined by an igneous rim surrounding a less heated core. This reflects the migration of a thermal front moving inwards (Fig. 8C), progressively melting phyllosilicates (Genge 2006). Due to the high enthalpy of dehydroxylation reactions (>521 kJ kg${ }^{-1}$; Llana-Fúnez et al. 2007), hydrated micrometeorites can support high thermal gradients $\left(>200 \mathrm{~K} \mathrm{\mu m}^{-1}\right.$; Genge et al. 2017). The four TAM micrometeorites in this study have well-developed igneous rims. During the early stages of atmospheric entry, heating a layer of melt would, therefore, have coated their exteriors and acted as a seal, preventing volatile gases liberated by decomposing phases, from escaping and forcing internal gas pressures to rise, as outlined in Taylor et al. (2011) and Genge (2017).

In TAM37P-03, interconnected channels are absent and instead, a thick igneous rim covers the particle's crystalline core. This rim has, however, split into isolated sections, causing the unmelted particle interior to be exposed. The newly exposed dark core also shows minor evidence of melting, resulting in the development of a thin, secondary igneous rim (Figs. 3E-G). Furthermore, we noted that rounded droplets are present on the particle exterior (Fig. 3C). Collectively, these observations require that the primary igneous rim broke apart, during atmospheric entry heating, while the rim was still partially molten. These conditions are necessary otherwise the secondary igneous rim could not have formed.

The polygonal arrangement of fissures on the surface of TAM37P-03 (Fig. 3) is similar to desiccation cracks in terrestrial environments and most likely formed by tensional forces ripping apart a brittle crust, as the micrometeoroid interior expanded outwards. Thus, the splitting of the primary igneous rim was driven by volume expansion, although this expansion may have been limited to only the micrometeorite's outer layers of fine-grained matrix. Rapid volume expansions occurring in micrometeoroids have previously been suggested by several studies. Most notably Genge (2017) demonstrated that scoriaceous micrometeorites rapidly expand in volume during partial melting, resulting in a vesicular parachute that decelerates the falling micrometeoroid. Likewise, Taylor et al. (2011) argued that dehydration cracks in micrometeorite matrix, which form by phyllosilicate contraction, later evolve by growth and expansion into vesicles. This process appears to be driven by the release of volatile gases and rising internal gas pressures within the micrometeoroid, which forces cavities open and causes expansion of the particle.

The formation of fissures within a melt layer, owing to extension, might seem less likely than thinning of the melt layer; however, vesicular foams are Bingham fluids that can be broken under low shear stresses and high strain rates (Wright and Weinberg 2009). Therefore, rapid expansion of the particle interior could produce the observed polygonal-shaped fissure network on the micrometeorite exterior. Once fissures are formed, the melt's surface tension may have also played a role in the withdrawal of melt away from the fissured areas. Gas release from the micrometeorite core is also likely to have prevented melt from flowing back.

Consequently, TAM37P-03 records the petrography of a micrometeorite shortly after the escape of volatile gases, generated within the fine-grained matrix layer 
Table 4. SEM-EDS analyses of micron-scale Fe-rich vesicle rim linings in TAM19-7. The suspected dominant phase is ferrihydrite (atomic ratio: $\mathrm{O} / \mathrm{Fe}=4$ ), although several related Fe-oxide, hydroxide, and oxyhydroxide phases such as ferric hydroxide $\left(\mathrm{Fe}[\mathrm{OH}]_{3}, \mathrm{O} / \mathrm{Fe}=3\right)$ are likely present, existing as a complex mixture and generalized by the term limonite.

\begin{tabular}{llllrllllllll}
\hline Analysis & $\mathrm{Na}$ & $\mathrm{Mg}$ & $\mathrm{Al}$ & \multicolumn{1}{c}{$\mathrm{Si}$} & $\mathrm{S}$ & $\mathrm{Cl}$ & $\mathrm{K}$ & $\mathrm{Cr}$ & $\mathrm{Fe}$ & $\mathrm{O}$ & Total & Atomic $\mathrm{O} / \mathrm{Fe}$ \\
\hline 1 & 0.7 & 0.7 & 2.2 & 4.5 & 5.5 & 1.1 & 0.4 & 0.2 & 38.5 & 48.3 & 102.0 & 4.4 \\
2 & 0.7 & 3.4 & 2.0 & 11.7 & 3.8 & 0.8 & 0.3 & 0.3 & 29.9 & 48.2 & 101.2 & 5.6 \\
3 & 0.5 & 1.2 & 1.9 & 6.6 & 4.0 & 0.9 & 0.0 & 0.4 & 42.6 & 41.1 & 99.1 & 3.4 \\
4 & 0.0 & 0.2 & 1.5 & 2.8 & 4.3 & 0.9 & 0.2 & 0.3 & 40.1 & 39.3 & 89.6 & 3.4 \\
5 & 0.4 & 2.1 & 2.0 & 6.6 & 4.9 & 0.8 & 1.1 & 0.2 & 35.3 & 42.4 & 95.7 & 4.2 \\
Average & 0.4 & 1.5 & 1.9 & 6.4 & 4.5 & 0.9 & 0.4 & 0.3 & 37.3 & 43.8 & 97.5 & 4.2 \\
\hline
\end{tabular}

below the igneous rim. Once the igneous rim was breached, gas exchange with the Earth's atmosphere occurred. The $\mu \mathrm{CT}$ data demonstrated that TAM37P-03 has both a high porosity $(\sim 13 \%)$, and that $64 \%$ of pores connect with the particle exterior. The total porosity in TAM37P-03 is, therefore, 2-3 times higher than the calculated matrix porosities of CI1, CR2, CM2, and the intensely aqueously altered CM2.0 chondrites (which range between 2 and $8 \%$ ), as measured by Corrigan et al. (1997). This porosity value is, however, consistent with previous measurements from unmelted micrometeorites $(0-12 \%)$, also measured using $\mu \mathrm{CT}$ and performed by Kohout et al. (2014), who demonstrated that micrometeorites in the later stages of atmospheric entry develop significantly higher porosities, up to $27 \%$. These lines of evidence demonstrate that the development of secondary porosity in micrometeorites is a major process during atmospheric entry. With continued heating and the onset of partial melting within the micrometeorite core, TAM 37P-03 is likely to have developed the same interconnected channels that are observed in the remaining three giant fine-grained TAM micrometeorites.

The establishment of interconnected pore space will necessarily allow the movement of expanding hot gases, which will modify the thermal gradients and result in a more rapid, convective heating regime. Gas migration is likely to initially occur inwards due to high ram pressures, while gas escape is prevented by the igneous rim. However, once the internal gas pressure is sufficient to breach the igneous rim, gas will then escape outwards.

In two of the micrometeorites (TAM19B-7 and TAM19-7), evidence of enhanced thermal processing along channel walls and in the matrix surrounding channels is observed and is consistent with the inwards migration of heat by gases. Iron-rich deposits, dominated by magnetite microcrystals, are found lining the channel walls of the largest voids; these are shown in Figs. 6 and 7. Such inner rims are most likely formed by the same mechanism that generates magnetite rims on unmelted micrometeorite exteriors; that is, by melting, evaporative depletion of volatile elements, oxidation, and subsequent cooling and crystallization (Toppani and Libourel 2003). The magnetite rims lining internal voids in TAM19B-7 (Figs. 6B and 6C) support this suggestion. However, the nonstochiometric Fe-rich rims, most likely composed of limonite, in TAM19-7 (Figs. 7B and 7C and Table 4) could, instead, represent later terrestrial weathering (Van Ginneken et al. 2016). In this case, these Fe-bearing deposits would not be indicative of the micrometeorite's initial Fe distribution. However, because the fine-grained matrix in close proximity to the channels also shows increased Fe content (Figs. 4B, 6D, 6E, 7D, and 7E), this further suggests enhanced thermal processing. In 2006, Genge suggested that increased $\mathrm{Fe} / \mathrm{Si}$ ratios within the igneous rims of small Antarctic micrometeorites, as compared to their unmelted cores resulted from the migration of Fe-S eutectic liquids under reducing conditions and, therefore, regions of $\mathrm{Fe}$ enrichment highlight zones which have experienced a greater degree of thermal processing (Genge and Grady 1998; Genge 2006). Therefore, the Fe enrichment adjacent to channels observed in these giant micrometeorites implies enhanced thermal processing resulting from gas-driven heating.

\section{Implications: The Fragmentation of Micrometeoroids}

Particles TAM-19B-7 and TAM2.1Q both have at least one surface without a magnetite rim suggesting these have been fractured. Fragmentation of these particles could, however, have occurred during transport on the Earth surface or during collection, instead of during atmospheric entry. Particle TAM19B-7 exhibits a planar segment on its external surface that is distinct from the lobate outline of the nonfractured surface. The planar segment also has a less well-developed magnetite rim than the lobate surfaces and lacks an igneous rim, testifying to a period of reduced heating. This straight boundary is interpreted as a dehydration crack that is terminated at one end by a second dehydration crack, orientated perpendicular to the first, and which itself penetrates into the micrometeorite. These features are 
consistent with the observation that some dehydration cracks bifurcate and implies that fragmentation of this micrometeorite occurred during atmospheric entry.

Variations in the development of magnetite and igneous rims in micrometeorite may arise owing to fragmentation during flight resulting in the exposure of new surfaces to heating. Parts of micrometeorites with less developed rims may, therefore, be similar to secondary fusion crusts observed on meteorites and formed by delamination and removal of areas of pre-existing crust (Genge and Grady 1998). In hydrated meteorites, this process may also be facilitated by dehydration cracks. Consequently, the thin regions of igneous and/or magnetite rims seen on TAM37P-03 should be considered secondary rims because they appear to have formed by exposure of the core to heating after fissures formed.

Although secondary melt rims and surfaces without signs of heating may form by fragmentation, preferred orientation during flight might also be expected to cause asymmetric heating effects. For example, exposure of a single micrometeorite face in the flight direction might be caused by stabilization of a spin axis, owing to the windmill effect (Genge 2016). However, flight orientation might be expected to result in a systematic variation in rim development and this is not observed in TAM37P-03. A fragmentation event is also likely to result in sudden changes in the velocity of particles and, therefore, has potential to create complex thermal histories such as those observed in this study.

Finally, the phenomenon of micrometeoroid fragmentation is supported by two additional and separate lines of evidence. (1) Rudraswami et al. (2012) previously reported the discovery of glassy cosmic spherules which show evidence of partial fragmentation, while in a molten state and during atmospheric entry. They argued that in large $(>300 \mu \mathrm{m})$ cosmic spherules, fragmentation begins by the development of a fissure along the particle's width. This is apparently driven by trapped superheated gases (e.g., steam) or by atmospheric compression. They, however, suggest that this process is important only in larger spherules which are molten. In contrast, our study describes the fragmentation of micrometeoroids in the solid state, driven by increasing internal pressures as a result of volatile gas release from decomposing low-temperature phases. (2) Additionally, the fragmentation of submillimeter particles during entry has also been observed from radar, both as distinct separation events and as quasi-continuous disintegration (Kero et al. 2008; Briczinski et al. 2009).

Current estimates suggest that fragmentation is an overlooked process with as many as $80 \%$ of the larger meteors $(>1 \mathrm{~cm})$ experiencing disruption (Gao and Mathews 2015). Thus, the paucity of large fine-grained micrometeorites (Van Ginneken et al. 2012) is likely a product of both fragmentation, as argued here, and the overproduction of smaller dust grains (typically $<100 \mu \mathrm{m}$ in diameter; Flynn et al. 2009).

\section{CONCLUSIONS}

This study investigated four giant unmelted micrometeorites, containing heated and thermally decomposed fine-grained matrix. Their petrography, geochemistry, and textures provide new insights into the early stages of atmospheric entry heating in unmelted micrometeorites:

1. Textural analysis, 3-D imaging, and geochemical data revealed the presence of abundant interconnected secondary pore space, composed of linked dehydration cracks and vesicles in three of the four micrometeorites. In several instances, wide, sinuous, and branching channels have evidence of increased thermal reprocessing adjacent to their channel walls. We argue that these channels form as dehydration cracks and vesicles link together. Although dehydration cracks are initially formed by the contraction of phyllosilicates, their later growth appears to be driven by volatile gas release, exerting pressure on pore walls and potentially leading to explosive expansion. Collectively, these features imply that the thermal decomposition of lowtemperature phases, during atmospheric entry, plays a critical role in the heating micrometeorite cores, primarily through the loss of conductive core-to-rim thermal gradients, which occurs as convective gas flow regimes are established.

2. Furthermore, the development of interconnected pore space promotes the fragmentation of larger micrometeoroids and could potentially explain the paucity of large, hydrated micrometeorites among collections.

Acknowledgments - The data presented in this paper were acquired during M. Suttle's Ph.D. research and funded by the Science and Technology Council (STFC) (ST/M503526/1). Matthew Genge and Sara Russell are funded by the STFC grants (ST/J001260/1 and ST/ M00094X/1, respectively), while Luigi Folco is funded by the Italian MIUR (grant PNRA16_00029 and PRIN2015_20158W4JZ7). We also thank John Spratt, Tomasz Góral, and Tobias Salge from the NHM and Tina Geriaki from Diamond Lightsource for their support during and analytical acquisition. Adam Suttle from Queen's College Oxford, UK is thanked for his help processing the CT video. Finally, Luke Daly from 
Glasgow University is thanked for his handling of samples and organization of analytical time.

\section{Editorial Handling-Dr. Michael Zolensky}

\section{REFERENCES}

Baldridge A. M., Hook S. J., Grove C. I., and Rivera G. 2009. The ASTER Spectral Library Version 2.0. Remote Sensing of Environment 113:711-715.

Bland P. A., Kelley S. P., Berry F. J., Cadogan J. M., and Pillinger C. T. 1997. Artificial weathering of the ordinary chondrite Allegan: Implications for the presence of $\mathrm{Cl}-$ as a structural component in akaganeite. Americian Mineralogist 82:1187-1197. https://doi.org/10.2138/am-1997-11-1215.

Bray H. J. and Redfern S. A. T. 1999. Kinetics of dehydration of Ca-montmorillonite. Physics and Chemistry of Minerals 26:591-600. https://doi.org/10.1007/s002690050223.

Briczinski S. J., Mathews J. D., and Meisel D. D. 2009. Statistical and fragmentation properties of the micrometeoroid flux observed at Arecibo. Journal of Geophysical Research: Space Physics 114:1-12. https://doi. org/10.1029/2009JA014054.

Buades A., Coll B., and Morel J. M. 2008. Nonlocal image and movie denoising. International Journal of Computer Vision 76:123-139. https://doi.org/10.1007/s11263-007-0052-1.

Che C. and Glotch T. D. 2012. The effect of high temperatures on the mid-to-far-infrared emission and near-infrared reflectance spectra of phyllosilicates and natural zeolites: Implications for Martian exploration. Icarus 218:585-601. https://doi.org/10.1016/j.icarus.2012. 01.005 .

Corrigan C. M., Zolensky M. E., Dahl J., Long M., Weir J., Sapp C., and Burkett P. J. 1997. The porosity and permeability of chondritic meteorites and interplanetary dust particles. Meteoritics \& Planetary Science 32:509-515. https://doi.org/10.1111/j.1945-5100.1997.tb01296.x.

Court R. W. and Tan J. 2016. Insights into secondary reactions occurring during atmospheric ablation of micrometeoroids. Meteoritics \& Planetary Science 51:11631183. https://doi.org/10.1111/maps.12652.

Dobrică E., Engrand C., Duprat J., Gounelle M., Leroux H., Quirico E., and Rouzaud J. N. 2009. Connection between micrometeorites and Wild 2 particles: From Antarctic snow to cometary ices. Meteoritics \& Planetary Science 44:1643-1661. https://doi.org/10.1111/j.1945-5100.2009.tb 01196.x.

El Maarry M. R., Kodikara J., Wijessoriya S., Markiewicz W. J., and Thomas N. 2012. Desiccation mechanism for formation of giant polygons on Earth and intermediatesized polygons on Mars: Results from a pre-fracture model. Earth and Planetary Science Letters. 323:19-26. https://doi.org/10.1016/j.eps1.2012.01.016.

Esser K. B. 1990. X-ray diffraction indices for relative quantification of interlayering in phyllosilicates. Soil Science Society of America Journal 54:923-926. https://doi. org/10.2136/sssaj1990.03615995005400030052x.

Flynn G. J., Durda D. D., Sandel L. E., Kreft J. W., and Strait M. M. 2009. Dust production from the hypervelocity impact disruption of the Murchison hydrous CM2 meteorite: Implications for the disruption of hydrous asteroids and the production of interplanetary dust.
Planetary and Space Science 57:119-126. https://doi.org/10. 1016/j.pss.2008.09.005.

Gao B. and Mathews J. D. 2015. High-altitude meteors and meteoroid fragmentation observed at the Jicamarca Radio Observatory. Monthly Notices of the Royal Astronomical Society 446:3404-3415. https://doi.org/10.1093/mnras/ stu2176.

Genge M. J. 2006. Igneous rims on micrometeorites. Geochimica et Cosmochimica Acta 70:2603-2621. https:// doi.org/10.1016/j.gca.2006.02.005.

Genge M. J. 2016. Vesicle dynamics during the atmospheric entry heating of cosmic spherules. Meteoritics \& Planetary Science 52:443-457. https://doi.org/10.1111/maps.12805.

Genge M. J. 2017. Vesicular parachutes increase the abundance of micrometeorites from water-rich asteroids on Earth. Geophysical Research Letters 44:1679-1686. https://doi.org/10.1002/2016GL072490.

Genge M. J. and Grady M. M. 1998. Melted micrometeorites from Antarctic ice with evidence for the separation of immiscible Fe-Ni-S liquids during entry heating. Meteoritics \& Planetary Science 33:425-434. https://doi. org/10.1111/j.1945-5100.1998.tb01647.x.

Genge M. J., Grady M. M., and Hutchison R. 1997. The textures and compositions of fine-grained Antarctic micrometeorites: Implications for comparisons with meteorites. Geochimica et Cosmochimica Acta 61:51495162. https://doi.org/10.1016/S0016-7037(97)00308-6.

Genge M. J., Gileski A., and Grady M. M. 2005. Chondrules in Antarctic micrometeorites. Meteoritics \& Planetary Science 40:225-238. https://doi.org/10.1111/j.1945-5100. 2005.tb00377.x.

Genge M. J., Engrand C., Gounelle M., and Taylor S. 2008. The classification of micrometeorites. Meteoritics \& Planetary Science 43:497-515. https://doi.org/10.1111/j. 1945-5100.2008.tb00668.

Genge M. J., Van Ginneken M., and Suttle M. D. 2017. Thermal shock fragmentation of $\mathrm{Mg}$-silicates within scoriaceous micrometeorites reveal hydrated asteroidal sources. Geology 45:891-894. https://doi.org/10.1130/G39426.1.

Genge M. J., Van Ginneken M., Suttle M. D., and Harvey R. P. 2018. Accumulation mechanisms of micrometeorites in an ancient supraglacial moraine at Larkman Nunatak, Antarctica. Meteoritics \& Planetary Science. https://doi. org/10.1111/maps.13107.

Glavin D. P. and Bada J. L. 2001. Survival of amino acids in micrometeorites during atmospheric entry. Astrobiology 1:259-269. https://doi.org/10.1089/15311070152757456.

Greshake A., Kloeck W., Arndt P., Maetz M., Flynn G. J., Bajt S., and Bischoff A. 1998. Heating experiments simulating atmospheric entry heating of micrometeorites: Clues to their parent body sources. Meteoritics \& Planetary Science 33:267-290. https://doi.org/10.1111/j. 1945-5100.1998.tb01632.x.

Hallis L. J. 2013. Alteration assemblages in the Miller Range and Elephant Moraine regions of Antarctica: Comparisons between terrestrial igneous rocks and Martian meteorites. Meteoritics \& Planetary Science 48:165-179. https://doi. org/10.1111/maps.12049.

Imae N., Taylor S., and Iwata N. 2013. Micrometeorite precursors: Clues from the mineralogy and petrology of their relict minerals. Geochimica et Cosmochimica Acta 100:116-157. https://doi.org/10.1016/j.gca.2012.09.052.

Kero J., Szasz C., Pellinen-Wannberg A., Wannberg G., Westman A., and Meisel D. D. 2008. Three-dimensional 
radar observation of a submillimeter meteoroid fragmentation. Geophysical Research Letters 35. https:// doi.org/10.1029/2007g1032733.

Ketcham R. A. and Carlson W. D. 2001. Acquisition, optimization and interpretation of X-ray computed tomographic imagery: Applications to the geosciences. Computers \& Geosciences 27:381-400. https://doi.org/10. 1016/S0098-3004(00)00116-3.

Kohout T., Kallonen A., Suuronen J. P., Rochette P., Hutzler A., Gattacceca J., Badjukov D. D., Skala R., Böhmová V., and Čuda J. 2014. Density, porosity, mineralogy, and internal structure of cosmic dust and alteration of its properties during high-velocity atmospheric entry. Meteoritics \& Planetary Science 49:1157-1170. https://doi. org/10.1111/maps.12325.

Kurat G., Koeberl C., Presper T., Brandstätter F., and Maurette M. 1994. Petrology and geochemistry of Antarctic micrometeorites. Geochimica et Cosmochimica Acta 58:3879_ 3904. https://doi.org/10.1016/0016-7037(94)90369-7.

Landis E. N. and Keane D. T. 2010. X-ray microtomography. Materials Characterization 61:1305-1316. https://doi.org/ 10.1016/j.matchar.2010.09.012.

LaPrade K. E. 1986. Climate, geomorphology, and glaciology of the Shackleton glacier area, Queen Maud Mountains, Transantarctic Mountains, Antarctica. Geology of the Central Transantarctic Mountains 36:163-196. https://doi. org/10.1029/AR036p0163.

Lin Q., Al-Khulaifi Y., Blunt M. J., and Bijeljic B. 2016. Quantification of sub-resolution porosity in carbonate rocks by applying high-salinity contrast brine using X-ray microtomography differential imaging. Advances in Water Resources 96:306-322. https://doi.org/10.1016/j.advwatres. 2016.08.002.

Llana-Fúnez S., Brodie K. H., Rutter E. H., and Arkwright J. C. 2007. Experimental dehydration kinetics of serpentinite using pore volumometry. Journal of Metamorphic Geology 25:423438. https://doi.org/10.1111/j.1525-1314.2007.00703.x.

Love S. G. and Brownlee D. E. 1991. Heating and thermal transformation of micrometeoroids entering the Earth's atmosphere. Icarus 89:26-43. https://doi.org/10.1016/00191035(91)90085-8.

Love S. G. and Brownlee D. E. 1993. A direct measurement of the terrestrial mass accretion rate of cosmic dust. Science 262:550-554. https://doi.org/10.1126/science.262. 5133.550.

Maurette M., Jehanno C., Robin E., and Hammer C. 1987. Characteristics and mass distribution of extraterrestrial dust from the Greenland ice cap. Nature 328:699-702. https://doi.org/10.1038/328699a0.

Merlet C. and Llovet X. 2012. Uncertainty and capability of quantitative EPMA at low voltage-A review. IOP Conference Series: Materials Science Engineering 32:1-15. https://doi.org/10.1088/1757-899X/32/1/012016.

Nesvorný D., Bottke W. F., Levison H. F., and Dones L. 2003. Recent origin of the solar system dust bands. The Astrophysical Journal 591:486-497. https://doi.org/10.1086/ 374807.

Nesvorný D., Vokrouhlický D., Bottke W. F., and Sykes M. 2006. Physical properties of asteroid dust bands and their sources. Icarus 181:107-144. https://doi.org/10.1016/j.ica rus.2005.10.022.

Nesvorný D., Jenniskens P., Levison H. F., Bottke W. F., Vokrouhlický D., and Gounelle M. 2010. Cometary origin of the zodiacal cloud and carbonaceous micrometeorites.
Implications for hot debris disks. The Astrophysical Journal 713:816-836. https://doi.org/10.1088/0004-637X/713/2/816.

Newbury D. E. and Ritchie N. W. M. 2012. Is scanning electron microscopy/energy dispersive X-ray spectrometry (SEM/EDS) quantitative? Scanning 35:141-168. https://doi. org/10.1002/sca.21041.

Noguchi T., Nakamura T., and Nozaki W. 2002. Mineralogy of phyllosilicate-rich micrometeorites and comparison with Tagish Lake and Sayama meteorites. Earth and Planetary Science Letters 202:229-246. https://doi.org/10.1016/S0012$821 \mathrm{X}(02) 00777-\mathrm{X}$.

Nozaki W., Nakamura T., and Noguchi T. 2006. Bulk mineralogical changes of hydrous micrometeorites during heating in the upper atmosphere at temperatures below 1000C. Meteoritics \& Planetary Science 41:1095-1114. https://doi.org/10.1111/j.1945-5100.2006.tb00507.

Peucker-Ehrenbrink B. 1996. Accretion of extraterrestrial matter during the last 80 million years and its effect on the marine osmium isotope record. Geochimica et Cosmochimica Acta 60:3187-3196. https://doi.org/10.1016/ 0016-7037(96)00161-5.

Rochette P., Folco L., Suavet C., Van Ginneken M., Gattacceca J., Perchiazzi N., Braucher R., and Harvey R. P. 2008. Micrometeorites from the transantarctic mountains. Proceedings of the National Academy of Sciences 105: 18,206-18,211. https://doi.org/10.1073/pnas.0806049105.

Rubin A. E. and Grossman J. N. 2010. Meteorite and meteoroid: New comprehensive definitions. Meteoritics \& Planetary Science 45:114-122. https://doi.org/10.1111/j. 1945-5100.2009.01009.x.

Rudraswami N. G., Prasad M. S., Babu E. V. S. S. K., Kumar T. V., Feng W., and Plane J. M. C. 2012. Fractionation and fragmentation of glass cosmic spherules during atmospheric entry. Geochimica et Cosmochimica Acta 99:110-127. https://doi.org/10.1016/j.gca.2012.09.036.

Salge T., Krzesinska A., and Mohr-Westheide T. 2017. Nondestructive imaging of Martian meteorite Chassigny and quantification of platinium group metals in Archean spherule layers in the Barberton Greenstone Belt, South Africa using FEG SEM/EDS. 80th Annual Meeting of the Meteoritical Society, July 23-28, 2017, Santa Fe, New Mexico (abstract \#6209).

Salisbury J. W. and Wald A. 1992. The role of volume scattering in reducing spectral contrast of reststrahlen bands in spectra of powdered minerals. Icarus 96:121-128. https://doi.org/10.1016/0019-1035(92)90009-V.

Schulz R., Stüwe J. A., and Boehnhardt H. 2004. Rosetta target comet $67 \mathrm{P} /$ Churyumov-Gerasimenko-Postperihelion gas and dust production rates. Astronomy \& Astrophysics 422: L19-L21. https://doi.org/10.1051/0004-6361:20040190.

Shen P., Hwang S. L., and Chu H. T. 1990. Defect microstructure and dehydroxylation mechanism of interstratified phyllosilicates: A TEM study. Journal of Materials Science 25:3072-3078. https://doi.org/10.1007/BF00587652.

Speck A. K., Whittington A. G., and Hofmeister A. M. 2011. Disordered silicates in space: A study of laboratory spectra of "amorphous" silicates. The Astrophysical Journal 740:93-110. https://doi.org/10.1088/0004-637X/740/2/93.

Steele I. M. 1992. Olivine in Antarctic micrometeorites: Comparison with other extraterrestrial olivine. Geochimica et Cosmochimica Acta 56:2923-2929. https://doi.org/10. 1016/0016-7037(92)90368-S.

Suavet C., Rochette P., Kars M., Gattacceca J., Folco L., and Harvey R. P. 2009. Statistical properties of the Transantarctic 
Mountains (TAM) micrometeorite collection. Polar Science 3:100-109. https://doi.org/10.1016/j.polar.2009.06.003.

Suttle M. D., Van Ginneken M., and Genge M. J. 2015. Larkman Nunatak micrometeorites, a statistical study. In 78th Annual Meeting of the Meteoritical Society, July 2731, 2015, Berkeley, California (abstract \#5063).

Suttle M. D., Genge M. J., Folco L., and Russell S. S. 2017. The thermal decomposition of fine-grained micrometeorites, observations from mid-IR spectroscopy. Geochimica et Cosmochimica Acta 206:112-136. https://doi. org/10.1016/j.gca.2017.03.002.

Taylor S., Lever J. H., and Harvey R. P. 1998. Accretion rate of cosmic spherules measured at the South Pole. Nature 392:899-902. https://doi.org/10.1038/31894.

Taylor S., Lever J. H., and Harvey R. P. 2000. Numbers, types, and compositions of an unbiased collection of cosmic spherules. Meteoritics \& Planetary Science 35:651666. https://doi.org/10.1111/j.1945-5100.2000.tb01450.x.

Taylor S., Matrajt G., Lever J. H., Joswiak D. J., and Brownlee D. E. 2007. Size distribution of Antarctic micrometeorites. Dust in Planetary Systems 643:145-148.

Taylor S., Jones K. W., Herzog G. F., and Hornig C. E. 2011. Tomography: A window on the role of sulfur in the structure of micrometeorites. Meteoritics \& Planetary Science 46:14981509. https://doi.org/10.1111/j.1945-5100.2011.01245.x.

Taylor S., Matrajt G., and Guan Y. 2012. Fine-grained precursors dominate the micrometeorite flux. Meteoritics \& Planetary Science 47:550-564. https://doi.org/10.1111/j. 1945-5100.2011.01292.

\section{SUPPORTING INFORMATION}

Additional supporting information may be found in the online version of this article:

Fig. S1. TAM37P-03 ( $\mu \mathrm{CT}$ data): Pore space reconstruction via segmentation with a histogram-based thresholding method.
Toppani A. and Libourel G. 2003. Factors controlling compositions of cosmic spinels: Application to atmospheric entry conditions of meteoritic materials. Geochimica et Cosmochimica Acta 67:4621-4638. https:// doi.org/10.1016/S0016-7037(03)00383-1.

Toppani A., Libourel G., Engrand C., and Maurette M. 2001. Experimental simulation of atmospheric entry of micrometeorites. Meteoritics \& Planetary Science 36:1377-1396. https://doi.org/10.1111/j.1945-5100.2001.tb 01831.x.

Tsai W. H. 1985. Moment-preserving thresholding: A new approach. Computer Vision, Graphics, and Image Processing 29:377-393. https://doi.org/10.1016/0734-189X (85)90133-1.

Van Ginneken M., Folco L., Cordier C., and Rochette P. 2012. Chondritic micrometeorites from the Transantarctic Mountains. Meteoritics \& Planetary Science 47:228-247. https://doi.org/10.1111/j.1945-5100.2011.01322.

Van Ginneken M., Genge M. J., Folco L., and Harvey R. P. 2016. The weathering of micrometeorites from the Transantarctic Mountains. Geochimica et Cosmochimica Acta 179:1-31. https://doi.org/10.1016/j.gca.2015.11.045.

Wright H. M. and Weinberg R. F. 2009. Strain localization in vesicular magma: Implications for rheology and fragmentation. Geology 37:1023-1026. https://doi.org/10. 1130/G30199A.1.

Zolensky M., Bland P., Brown P., and Halliday I. 2006. Flux of extraterrestrial materials. In Meteorites and the early solar system II, edited by Lauretta D. S. and McSween H. Y. Tucson, Arizona: The University of Arizona Press. pp. 869-888.

Fig. S2. TAM37P-03 ( $\mu \mathrm{CT}$ data): 3-D visualization of TAM37P-03, showing all tomographic slices through this particle. 